\title{
MARKET REACTION TO PUBLIC INFORMATION: THE ATYPICAL CASE OF THE BOSTON CELTICS
}

\author{
Gregory W. Brown* \\ Kenan-Flagler Business School \\ The University of North Carolina at Chapel Hill \\ and \\ Jay C. Hartzell \\ Stern School of Business \\ New York University \\ First Version: October 1995 \\ This Version: June 1999
}

\begin{abstract}
The publicly-traded Boston Celtics Limited Partnership shares provide a unique means of studying the impact of information on equity prices. The results of the Celtics' basketball games significantly affect partnership share returns, trading volume, and volatility. Controlling for the expected value of the signal using betting-market point spreads has little effect on these relations. Investors respond asymmetrically to wins and losses, and playoff games have a larger impact on returns than regular-season games. Because Celtics' games occur exclusively when the market is closed, we are able to analyze if game information is incorporated into prices during market closures. Opening prices do not fully reflect game results. This is consistent with the conclusions of previous research that significant volatility is caused by traders acting on private information.
\end{abstract}

JEL Classification: G14

Keywords: Information Effects, Investor Expectations, Volatility, Boston Celtics, Betting Markets

* Please address correspondence to Gregory W. Brown, Kenan-Flagler Business School, The University of North Carolina at Chapel Hill, CB 3490, McColl Building, Chapel Hill, NC 27599-3490, phone: (919) 962-9250, fax: (919) 962-2068, E-mail: browngr@icarus.bschool.unc.edu. We would like to thank Bill Schwert (the editor) and an anonymous referee for their extensive feedback and guidance. We are also indebted to Laura Starks, John Butler, Paul Cacciatore from the Boston Celtics, Ramon DeGennaro, Robert Harris, Bob Livingston of the Sports Weekly Newsletter, Brian Prucyk, Klaus Toft, and Kristina Zvinakis for their help and comments. Furthermore, seminar participants at the 1998 American Finance Association meetings, the 1996 Financial Management Association Annual Meeting, and a research seminar at The University of Texas at Austin improved the paper through their comments. 


\title{
MARKET REACTION TO PUBLIC INFORMATION: THE ATYPICAL CASE OF THE BOSTON CELTICS
}

\begin{abstract}
The publicly-traded Boston Celtics Limited Partnership shares provide a unique means of studying the impact of information on equity prices. The results of the Celtics' basketball games significantly affect partnership share returns, trading volume, and volatility. Controlling for the expected value of the signal using betting-market point spreads has little effect on these relations. Investors respond asymmetrically to wins and losses, and playoff games have a larger impact on returns than regular-season games. Because Celtics' games occur exclusively when the market is closed, we are able to analyze if game information is incorporated into prices during market closures. Opening prices do not fully reflect game results. This is consistent with the conclusions of previous research that significant volatility is caused by traders acting on private information.
\end{abstract}




\section{Introduction}

Typical value-relevant information signals are revealed to markets in an infrequent and potentially confounding way. Even the most frequent of regular signals, such as earnings announcements, occur only a few times per year. The information is commonly revealed during trading hours, and even when investors expect an announcement, they are often forced to rely on proxies for the market's expectations (e.g., mean analysts' forecasts). Of interest would be a case where the signals are very frequent, easy to quantify, occur solely when the market is closed, and have observable ex ante expectations.

The Boston Celtics Limited Partnership (LP) provides a case. Their partnership shares are publicly traded, providing observable prices and returns. Eighty-two times a year (not including playoffs), its team, the Celtics, plays a basketball game as part of the National Basketball Association (NBA) schedule. These games provide a regular measuring stick for the team's performance, which we in turn find to be related to the firm's operating performance. The expected outcome of each game is known and observable, by virtue of the sports betting market. The games occur exclusively when the stock market is closed, allowing easier isolation of their impact on the variation in trading patterns.

This paper has two main goals. At a general level, we seek to better understand how markets incorporate publicly available information. For example, does the timing of signals -- here, basketball games -- offer further evidence on when markets incorporate information revealed during market closures? Furthermore, at the individual-firm level, we examine the informational impact of game results on the value of the Boston Celtics LP. Specifically, we seek to determine if, how, and when the market reacts to the outcome of these (potentially) valuerelevant signals.

We analyze a sample of game results, point spreads, trading volume, returns and volatility of the Celtics partnership shares from January 1, 1987 to May 31, 1998. We find that volume and volatility are higher during the season as a whole and on days that follow games. Returns reflect game results, and losses drive the relations during the regular season. Playoff games have a significant, incremental impact on returns, but this effect is found for both 
wins and losses. Finally, we show that the increased volatility associated with games largely occurs when the market is open, even though the games occur when the market is closed. We interpret this as new evidence that much of the difference between open- and closed-market volatility can be attributed to traders acting on private information.

The next section describes our data. Section 3 presents our hypotheses, empirical tests, and results. Section 4 discusses the possible implications of the games' atypical timing. In section 5 , we explore the impact of two non-game events: the building of the new Boston Garden and the hiring of head coach Rick Pitino. Section 6 concludes the main text. We summarize the results of several robustness checks in a short appendix.

\section{Data}

The Boston Celtics were first listed for public trading on the New York Stock Exchange on December 4, 1986. In order to allow a few weeks for prices and volume to settle following the initial public offering, our sample covers the period from January 1, 1987 through May 31, 1998. Our sample covers twelve seasons (eleven of which are complete), and NBA teams play 82 games each regular season. We exclude games for which no point spreads are available. The resulting sample contains 2,884 daily returns and 1,032 games.

Daily returns and trading volume for the Boston Celtics Limited Partnership are taken from the Center for

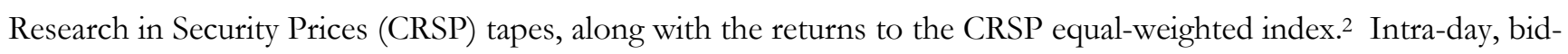
ask and open-to-close data are taken from The New York Stock Exchange Trade and Quote (TAQ) Database for 1993 through May 1998. Daily opening, high, and low prices are from Prophet Data Services. Point spreads are from the Las Vegas betting market, as given in Livingston (1990, 1992, and 1995) and by the Gold Sheet, an internet

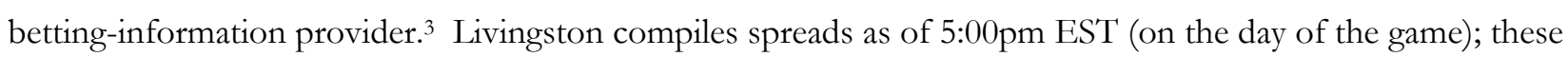

1 Although other studies have omitted longer periods, inspection of the data led us to believe that a few weeks was sufficient. By this time, volume and volatility had settled to levels near their sample average.

2 At this date, CRSP data are not available for the 1998 portion of the sample. For this period, Celtics data is from Datastream, and we proxied for the CRSP equal-weighted index with the Wilshire 5000; the correlation between the two indices' daily returns is 0.88 .

${ }^{3}$ Livingston stopped publishing his books on the NBA spreads after the 1995 season. 
spreads should capture the vast majority of bettors' expectations. Table 1 contains descriptive information about the returns and the Celtics on-the-court performance over the sample period. The first rows show the means of both the market and Celtics' returns, as well as the Celtics' win-loss record, against and ignoring the spread. Note that for this sample, the point spread is an extremely good predictor of game outcome on average. Versus the spread, the Celtics had 498 wins and 499 losses over the 12 seasons.

\section{[Please insert Table 1 about here]}

The Celtics' shares are not heavily traded. 1 Daily trading volume averages roughly 4,400 shares over our entire sample period. The 1993-1998 TAQ data shows an average of about 12 transactions a day, with an average trade size of 350 shares. The average market capitalization over the full sample period is roughly $\$ 115$ million, with an average of 6.2 million shares outstanding. The amount of institutional ownership is small with no institutional investor holding more than $1 \%$ of shares outstanding.

\section{Do Games Matter?}

There is ample evidence that publicly announced and unanticipated firm-specific information has an effect on stock prices (e.g., Malkiel, 1989) as do more frequent value-relevant signals, such as the stock-price effect of quarterly earnings announcements (e.g., Joy et al., 1977). Even at their most frequent, though, these studies address events that occur only a few times each year and their effect is often confounded with other contemporaneously revealed signals.

The Celtics provides an interesting study of how easily observed and measured information affects the

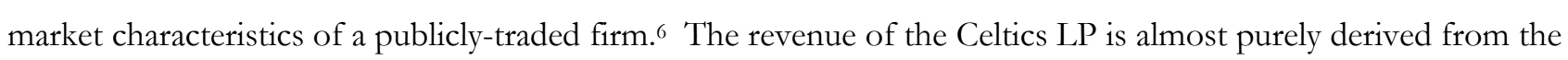

${ }^{4}$ While the traded securities are limited partnership units, for ease of exposition, we will use units and shares interchangeably, as well as replace unitholder with stockholder.

5 As of October 1998, Bloomberg listed total institutional holdings as approximately $0.3 \%$ of the total shares outstanding.

6 As a publicly-traded partnership, there are few substantive differences between the Celtics and a typical corporation. One exception is taxation; as a publicly traded partnership, the Celtics partnership shares are subject to slightly different taxation 
operations of the basketball team. Consequently, the games (as a visible indicator of team performance) contain information about a large percentage of the firm's operations. The games' frequency allows us to more confidently ignore structural changes in the firm or economy that may confound results from studies using less frequent data. For example, one year of games provides as many signals as about 20 years of quarterly earnings announcements.

Investors in typical stocks receive performance signals through such means as analysts' reports, news announcements, and periodic operating results. In contrast, shareholders of the Boston Celtics can, at least 82 times per year, open the sports pages and check how their investment is doing. Further, few other companies feature television and radio broadcasts of business activities and such widespread public debate over successes and failures. So, the first question we address is whether or not the market responds to these signals. That is, do investors use game results to revise their expectations of future cash flows?

This begs the question of why people invest in sports franchises and specifically, the Celtics. While one's motivation for buying stock in a Fortune 500 firm is most probably financial, owning part of a sports franchise may or may not be fundamentally different. For example, many owners of sports franchises receive extensive media coverage from their teams' exploits. The utility they derive from such exposure, as well as utility from winning -even "at all costs" -- could confuse the relations between financial (or team) performance and franchise value. That said, Celtics' shareholders, due to the diluted nature of their claim, cannot realistically expect to benefit from ownership to the extent the majority owner of a sports team can (e.g., the attention garnered by Jerry Jones of the Dallas Cowboys). They also receive virtually no control rights due to their limited partner status. Celtics' shareholders may however just want to own a piece of the team, possibly to be able to put a stock certificate on the wall, and this demand may be independent of the financial fortunes of the franchise. However, this type of demand

rules than ordinary common stock. Since the partnership was formed prior to 1987, it was treated as a partnership for tax purposes during the sample period. So, income was taxed (once) at the individual level, independent of the cash distributed during the tax year. This will change in tax years after 1997, when all publicly traded (or master) limited partnerships will be treated as a corporation for tax purposes (see Jones and Sommerfield, 1993, for a non-technical discussion, or I.R.C. § 7704). The other possibly material difference is in the area of agency considerations. For example, given their "limited" status, it might be very difficult for limited partners to replace the general partner should they desire to do so. 
could be satisfied by a very small number of shares and would seem unlikely to lead to significant trading.

Therefore, we hypothesize that the trading behavior of the Celtics' shares (e.g., returns, volume and volatility) is a function of the financial performance of the firm. ${ }^{3}$ Due to evolving expectations of the firm's fortunes and the plethora of available definitions of financial performance, it is difficult to directly test this hypothesis with a sample of our size (10 full fiscal years of data). The data do seem consistent with this hypothesis, however. For example, returns on the Celtics shares during the season ending in year $t$ have a positive significant statistical relation with the firm's income from continuing operations in fiscal year $t+1$ (results not reported). This is consistent with investors trading on their expectations of future performance (and those expectations being accurate on average).

Operating under the belief then that trading in the Celtics' shares is a function of the financial performance of the firm, it remains an open question whether the financial performance of the firm is in turn a function of the team's performance (i.e., winning versus losing). For some franchises (e.g., the Chicago Cubs), there may not be a positive relation. They may not need a winning team in order to maximize firm value; they may be more profitable by fielding a fairly competitive, but less expensive team.

However, there are many reasons why game results might affect cash flows. First, winning may lead to better game attendance, and therefore, more revenue. For the Boston Celtics, this may be a limited effect, as during most of the sample period, their home games were sold out. However, winning teams should be able to increase ticket prices more than losing teams, ceteris paribus. Also, continued fan interest, due at least in part to the team's successful track record, has most certainly contributed to the Boston area's construction of a new arena, where the Celtics began play in 1995. This new venue added dramatically to the ticket sales revenue of the team, boosting it

\footnotetext{
${ }^{7}$ We still cannot erase the possibility that the firm's performance in the market is disconnected from its value to its owners. A win-at-all-costs attitude, present or not, in the Celtics (or any other firm) is most difficult to detect.

${ }^{8}$ To be more specific, this could be thought of as changes in expectations of future performance, or deviations in realized performance from expectations.
} 
from approximately $\$ 22$ million during the last year in the Boston Garden to $\$ 35$ million during the first year of play in the new Fleet Center (the 1995-6 season). The increased capacity was a double-edged sword, however. During the Celtics' second year in the new arena, the team's record fell to 15 wins and 67 losses, leading to the only decline in ticket sales revenue in our sample (from $\$ 35$ million to less than $\$ 32$ million).

Winning can also have a potentially large effect on ticket revenue through the terms of leasing of luxury boxes and suites. For example, as the most successful NBA team of the 1990s the Chicago Bulls were able to sell lucrative multi-year leases for their suites when they moved into their new arena. In contrast, the Golden State Warriors were saddled with poor recent on-the-court performance and were forced to offer one- and two-year leases (for less money per year) when their new venue opened.

Advertising and licensing revenue is another source of income that is likely to be closely tied to team performance. Successful teams should be able to attract more viewers and potential customers for clients as well as sell more team-related items. For the NBA, such effects are on the local level. National television contracts and licensing revenues are shared across all teams, independent of their respective records. Teams are free, however, to negotiate local media deals and also keep any profits from merchandise sales in their franchise-owned stores. Thus, teams' revenue from advertising packages and to a lesser magnitude, merchandise, is indirectly a function of how well they play.

A large (and immediate) variable source of revenue that depends on winning games is the playoffs. If most home games are sellouts, and the team plays a fixed number of home games each regular season, then the playoffs are the only way to dramatically increase the current year's game revenue. Over the entire sample, the net revenue per playoff game for the Boston Celtics was approximately $\$ 200$ thousand. Whether or not the team makes the playoffs, and how far it goes into the playoffs, can have a significant impact on the year's earnings. For example, in 1992, the net income applicable to the Celtics' limited partners was $\$ 1,149,285$. For the same year, the net income from the playoffs was $\$ 1,733,818$. Thus, making the playoffs turned an annual loss of $\$ 0.09$ per share into a profit of $\$ 0.18$ per share. 
Aside from the more direct impact on cash flows, winning could have an impact on the value of the franchise through the value of its reputation. Many studies have found that corporate conduct, for example, has a significant impact on the value of firms (for examples, see Barber and Darrough, 1996, and the references therein). The Celtics have a proud and illustrious history, including 16 league titles, and two of the top 10 teams in history (as selected by a panel of sportswriters). By winning, the Celtics could add to or maintain their "goodwill" or franchise value, and losing could detract from that value that was built over the years before their public offering.

\subsection{The Relation Between Winning, Value and Income: Empirical Evidence}

Ultimately, the links from firm or franchise value to cash flows and to team performance is an empirical question. We address this question in two stages. First, we test for relations between team performance and estimated franchise values and net income using panel data from teams of the National Football League (NFL), Major League Baseball, and the NBA. Second, we look for relations between the Celtics' performance and their cash flows.

To test for a relation across several sports franchises, we use data from Financial World s annual valuation of major sports franchises. Their analysis, done from 1991 to 1997, produces estimates of operating income (including gate receipts, media revenue, stadium revenues, player salaries, and operating expenses) and franchise value for each team. Table 2 shows the results of random effects regressions of franchise value and operating income for a given year on winning percentages for the two most recent seasons. The random effects control for team-specific unobserved variables, such as market size and lease arrangements. We also included (but do not show) dummy variables for each sport-year in order to control for sport-wide effects (e.g., player strikes).

Column (1) of Table 2 presents the results for regressions of franchise value (in millions) on the prior two seasons' winning percentages. The relation between lagged winning percentage and franchise value is positive and 
significant at the $1 \%$ level. A 10 percentage-point increase in a team’s winning percentage is associated with a $\$ 2.6$ million increase in franchise value the following year. This may be the result of Financial Worlds methodology; the multipliers they use for franchise income may implicitly reflect the team's performance. A measure of financial performance that is less dependent on their judgement is operating income, which does not depend on a subjective multiplier. Column (2) of Table 2 presents regressions of franchise operating income on the previous two seasons' winning percentages. The results are consistent with those in column (1); lagged winning percentage has a significant (at the 1\% level), positive relation with operating income. A 10 percentage-point increase in a team's winning percentage is associated with a $\$ 740$ thousand increase in operating income the following year.

\section{[Please insert Table 2 about here]}

To test for a similar relation for the Celtics alone, we regress changes in net basketball revenue for the Celtics LP on the number of wins in the prior season, plus a dummy variable set to one for the year of the stadium change. We define net basketball revenue as regular-season plus playoff revenues minus the sum of regular-season costs, playoff costs, general and administrative expenses, and selling and promotional expenses. While the data here are certainly limited (we only have financial data for the fiscal years 1986-1997), the evidence is consistent with a positive relation between winning and cash flows. In column (3) of Table 2, we use the change in net basketball revenue per share as the dependent variable, and exclude playoff-related income and expenses. The number of wins in the prior year is significant at the $5 \%$ level and the coefficient implies that an extra win in year $t$ is associated with almost $\$ 0.06$ per share increase in net revenue from year $t$ to $t+1$. Column (4) presents results for changes in net basketball revenue (including playoffs) as the dependent variable. Here again, the results are significant at the 5\% level; an extra win is associated with almost $\$ 290$ thousand increase in net revenue. The results in Table 2 suggest that winning sports franchises, in general and for the Celtics specifically, are profitable. Furthermore, subject to the

${ }^{9}$ A Hausman test for the random effects failed to reject the null hypothesis of no relation between the regressors and the error terms.

${ }^{10}$ Our goal in constructing this measure is to exclude discontinued operations, as well as taxes and interest expenses. 
Financial World estimates, winning increases franchise value.

Even if games have information about future cash flows from the firm, transactions costs could wash away any observable effect on the Celtics' share price. Since acting on information is costly, investors may accumulate information until their revisions are large enough to justify action. Such accumulation would imply a negligible effect on a game-to-game basis. This line of reasoning leads to our first testable null hypothesis:

H1: Returns and trading activity (e.g., volume and volatility) in the shares of the

Boston Celtics LP are unrelated to team performance (i.e., game results).

In other words, "games don't matter." The alternative hypothesis is that trading activity is related to team performance.

\subsection{Evidence from Volume and Volatility}

There are many ways to test the hypothesis, but the simplest is to examine if trading volume and volatility are different (1) during the season and (2) on trading days after games. Table 3 shows that mean daily trading volume is higher during the basketball season. -1 Using a nonparametric Mann-Whitney (U) test, the difference between on-season and off-season trading volume is significant at the 1\% level. Furthermore, at the 5\% level, the average volume for days following games (5,419 shares) is higher than that of all other trading days (4,043 shares), and trading days during the season which did not follow a game (4,341 shares).

[Please insert Table 3 about here]

We also test whether volatility differs across these sub-samples by calculating the daily variance of returns using the Garman and Klass (1980) "Best" Analytic Scale-invariant Estimator. The advantage of this estimator is

\footnotetext{
11 We define the Celtics season as the period from two weeks before the first regular season game (to include some preseason information) to the last game the Celtics play.
} 
that it incorporates daily opening, high, low, and closing prices yielding a more accurate estimate than simple closeto-close estimators. The formula for this "Best" estimator of day $t$ variance is

$$
\hat{\sigma}_{t}^{2} \equiv 0.511\left(u_{t}-d_{t}\right)^{2}-0.019\left[c_{t}\left(u_{t}+d_{t}\right)-2 u_{t} d_{t}\right]-0.383 c_{t}^{2}
$$

where $u_{t}, d_{t}$, and $c_{t}$ are daily high, low, and closing prices divided by the opening price.

Using equation (1), the mean volatility (standard deviation) for the sample is $15.38 \%$. As Table 3 shows, the mean volatility during the season is higher than that of the off-season; the difference is significant at the $1 \%$ level. Likewise, mean volatility is higher on trading days following games $(16.22 \%)$ compared to all other days $(15.06 \%)$ and on-season, no-game days (15.26\%), and both differences are significant at the 5\% level. Both the volume and volatility tests support the hypothesis that the Celtics' games matter to investors, and there is an ordering of both measures of trading activity. The least activity occurs on off-season days, followed by on-season days that do not follow a game, with the most activity occurring during the season, on days following games. These statistics on volume and variance strongly reject $\mathrm{H} 1$ in favor of its alternative: yes, games do matter.

\subsection{Evidence from Returns}

In addition to volume and volatility, games may affect returns. Of course, in an efficient market, if shares are trading on financial performance, and financial performance is in turn based on the team's performance, the expected team results should be incorporated into the share price before the games are played. If the Celtics win, but the market expected them to, the game may have no new information about the firm's future cash flows. Consequently, there is no reason to expect a strong relation between game outcomes that are unadjusted for the expected result and changes in the Celtics' share price. The obvious way to capture these market expectations is to use the betting-market point spreads.

12 The authors show that this estimator yields an estimate of variance about 7.4 times more efficient than an estimator using only close-to-close data. 
Intuitively, point spreads should reflect expected point differences. Gamblers benefit from private information or superior ability to predict game outcomes, and through betting their beliefs are incorporated into the betting market's analog to price, the point spread. Betting market participants have incentives to bet until the spread matches their assessment of the expected outcome (within a range dictated by transaction costs). So, the final spread should be a good measure of informed investors' consensus opinion of the likely outcome.

This is an empirical question, one that has been examined at length in the betting market literature (see Sauer (1997) for a review of that literature). With a couple of exceptions, the empirical evidence supports the assertion that point spreads are unbiased predictors of game outcomes. In his survey of the betting-market literature, Sauer (1997) concludes that "as a rule, point spreads are efficient estimates of the median of the distribution of score differences" (Sauer, 1997, page 71). The results of earlier studies utilizing small samples were not so promising. For example, Zuber et al. (1985) and Amoako-Adu et al. (1985) find little evidence of a statistical relation between point spreads and actual outcomes. However, later studies use larger samples of NFL and NBA games and find greater evidence of an efficient betting market. Sauer et al. (1988), Gandar et al. (1988), and Dare and McDonald (1996) cannot reject the null hypothesis that the betting market is efficient, at least to the point where profit opportunities exist.

In addition to this evidence, other strands of the betting market literature provide further support for the use of point spreads in the study here. First, while there is some evidence of in-sample trading rules that take advantage of possible inefficiencies in the point-spread market, due to transaction costs or out-of-sample results, such rules do not appear to be inconsistent with an efficient market. For example, Camerer (1989) finds that bettors in the basketball market irrationally believe in the "hot hand," but that the observed irrationality is not large enough for a bettor to profitably exploit. Another example is the apparently profitable trading rules of Zuber et al. (1985), whose results are not robust to out-of-sample tests (Sauer et al. (1988)). Secondly, point spreads for NBA 
games have been shown to move in the direction of the actual outcome (Gandar et al. (1998)). Finally, Brown and Sauer (1993) find that errors from a point-spread model appear related to fundamentals rather than noise.

Thus, it seems reasonable to operate under the assumption that the NBA betting market is efficient. 4 Consequently, we propose a second related hypothesis:

H2: The return-relevant measure of team performance is the unexpected outcome, or the game result net of the point spread.

In a world free of transactions costs, a violation of $\mathrm{H} 2$ could be thought of as an arbitrage opportunity. That is, if the share price reacted to game outcome, but did not reflect the betting market's expectations, one could hedge one's stock market position via the betting market and expect to capture returns in at least one set of possible outcomes. 5 However, there are significant transaction costs in the Las Vegas betting market, characterized by the “eleven for ten rule", where one must bet $\$ 11$ to receive $\$ 10$ upon winning. Combined with the bid-ask spread faced by investors trading Celtics' shares, these costs make violations of H2 unlikely to generate any realistic arbitrage opportunities.

That said, testing this hypothesis is also a means of testing a type of market integration. We are trying to assess whether the two markets of interest, the stock market and the betting market, reflect similar expectations. The betting market provides a clean signal of these expectations via the observable point spread, leaving the question of whether the stock market is incorporating the same expectations. By isolating the Celtics' results net of expectations (point spreads) and looking for a market reaction to this "net" information, we address that question.

13 A study reaching a different conclusion is Golec and Tamarkin (1991). See Sauer's (1997) review article for a discussion of the difficulties in interpreting their results.

${ }^{14}$ As an example, for our sample of 1,032 games, the average margin of victory net of the point spread was less than a quarter of a point, and bets on the Boston Celtics against the spread won almost exactly $50 \%$ of the time (see Table 1).

${ }^{15}$ For example, if the Celtics were favored to win, but the stock price responded to the actual game outcome, one could buy the stock and bet against the Celtics. If the Celtics lost, depreciation in the stock would be offset by betting winnings. If they won by an amount greater than the spread, gains in the stock would offset losses on the bet. If the Celtics won, but did not beat the spread, the above strategy would profit on both the stock position and the bet. 
To test for the relation between returns and game outcomes, we first regress the Boston Celtics' daily returns on the CRSP equal-weighted market index returns, using the entire sample period. The residuals from this regression, labeled Abnormal Returnt, capture the return not explained by the market and the Celtics' covariance with the market. Panel A of Table 4 gives the mean abnormal returns for days following games, grouped by the wins and losses (absolute and spread-adjusted).

[Please insert Table 4 about here]

It is clear that different outcomes lead to different average returns. Regardless of the outcome against the spread, unadjusted wins yield positive returns and unadjusted losses yield negative returns. Winning the game results in a positive price change, independent of the outcome versus the spread. Similarly, losing the game results in a negative average return, regardless of the outcome versus the spread (although the average return in the event of a win versus the spread is very small). On the surface these results seem to indicate that it is the unadjusted game outcome that matters rather than the results against the spread. Table 4 also shows the significance of differences between mean returns. For example, winning the game and beating the spread results in a significantly higher return than losing the game and losing against the spread.

Another way of analyzing the importance of actual outcomes versus ex ante expectations is to partition trading days into four groups based on whether the Celtics are expected to win or lose and whether they actually

${ }^{16}$ Given the Celtics' size, using the equal-weighted index to capture relevant market effects makes intuitive sense. Using the value-weighted index or the S\&P 500 index return lowered the $R^{2}$ s and $t$ statistics from the regressions, but did not change the significance of the variables. The estimated market model was RETURN $=0.00030+0.29167 *$ EWRETD, where RETURN is the Celtics' daily return, and EWRETD is the daily return on the CRSP equal-weighted index. The market coefficient is significant at the $1 \%$ level.

${ }^{17}$ For panel A of Table 4, we sum the point differences and spreads over all games since the last trading day. For example, consider a weekend where the Celtics were favored by five points Friday night and seven-point underdogs on Sunday. If they won Friday by five points and lost Sunday by six, then the Celtics "lost" for the weekend, but "won" against the spread. In other words, positive summed point differences are "wins" and positive summed spreads indicate an expected "loss." For Panel B, returns count toward all appropriate groups (e.g., if over the weekend the Celtics unexpectedly lost, and had an expected win, the Monday return would be included in both of these groups). 
win or lose.1 1 The four possible combinations are expected win (denoted E[Win]:Win), unexpected loss (denoted E[Win]:Loss), unexpected win (denoted E[Loss]:Win), and expected loss (denoted E[Loss]:Loss). Panel B of Table 4 shows the results of this analysis. Notice the signs are as we naively would expect given the categorical breakdowns. A win results in a positive average abnormal return and a loss in a negative average abnormal return. Surprisingly, an unexpected win results in a smaller positive price change than an expected win. Difference in means tests show that only the differences between actual wins and losses are significant. These results offer only moderate support for the hypothesis that the stock market's expectations are reflected in the point spreads. If both markets have the same expectations (assuming that the point spread is an unbiased estimator of expected outcome), one would expect a greater (more negative) return for an unexpected win (loss) than an expected win (loss). Counter to this hypothesis, expected wins are associated with bigger returns on average than unexpected wins, but unexpected losses do have more negative returns than expected losses. Note that neither of these differences is statistically significant.

To further test our predictions concerning the role of investor expectations (H2), we can examine to what degree the signal received was expected (and equivalently, unexpected). To proxy for the magnitude of unexpected game results, we construct a variable labeled Cumulative Spread, which for a given trading day equals the cumulative points by which the Celtics beat (or lost to) the point spread since the last trading day. An analogous variable, Cumulative Pointst, equals the cumulative points by which the Celtics won or lost since the last trading day, ignoring the point spread. Hypothesis H2 can be tested by determining if Cumulative Spread, the spread-adjusted results, has a stronger relation with returns than Cumulative Pointst, the results unadjusted for expectations.

We use Abnormal Returnt as the dependent variable in the following regressions. The sample for these regressions is limited to days after games are played (i.e., trading days when games were played since the last market

\footnotetext{
${ }^{18}$ As alternatives to the above definitions of winning and losing, we tried partitioning returns in the manner used in Panel A and discussed in the footnote above. As another alternative, we excluded any return for which different outcomes had
} 
close). 1 To test for a relation between the returns and game outcomes, we regress Abnormal Return on Cumulative

Spread, i.e.,

$$
\text { Abnormal Return }_{t}=\alpha_{0}+\alpha_{1} \cdot \text { Cumulative } \text { Spread }_{t}+\varepsilon_{t} .
$$

We then replace Cumulative Spread with Cumulative Points in the regression, for an alternative model,

$$
\text { Abnormal Return }_{t}=\beta_{0}+\beta_{1} \cdot \text { Cumulative Points }+\varepsilon_{t} \text {. }
$$

Thus, under H1's alternative (returns reflect game results) and H2 (point spreads capture stock market's expectations), we expect the $\alpha_{1}$ coefficient in equation (2) to be positive, and it should be larger (and more significant) than the $\beta_{1}$ coefficient in equation (3). Another confirmation of $\mathrm{H} 2$ would be a higher $\mathrm{R}$-squared for the equation (2).

[Please insert Table 5 about here]

These results are summarized in columns (1) and (2) of Table 5. The estimated $\alpha_{1}$ and $\beta_{1}$ coefficients are both significantly different from zero at the $5 \%$ and $1 \%$ levels, respectively. for the spread-adjusted variable is larger than the one for the unadjusted variable $\left(8.24 \times 10^{-5}\right.$ versus $\left.7.00 \times 10^{-5}\right)$, but slightly less significant ( $\mathrm{p}$-value of 0.014 versus 0.009 ). The point-spread-adjusted coefficient indicates that the expectations captured by point spreads explain returns only marginally better than the naive estimator.

Consequently, it is not clear how much value-relevant information point spreads capture, and we cannot reject $\mathrm{H} 2$

occurred since the last trading day. For both of these alternatives, the (unreported) results were qualitatively very similar. ${ }^{19}$ There were 793 trading days that followed games. Due to the nature of the regressions, the estimates are virtually identical when run over all of the days. In this case, the independent variables take on zero values on days other than postgame trading days.

${ }^{20}$ While these coefficients are very small in magnitude, it is important to remember that they represent change in return for a one-point change in game outcome. Thus, holding all else constant, beating the spread by twelve points would predict about a $0.10 \%$ higher return for the next day than matching the spread. While this is less than transaction costs, it is not small compared to the mean daily return for the Celtics of $0.044 \%$. 
(expected outcomes matter) for its alternative. As above, these results reject the hypothesis that there is no relation between the Celtics' return and the game outcomes (H1).

Due to the multicollinearity between the spread-adjusted outcome and the unadjusted outcome, it is not possible with the sample size we have to detect separate effects of these two variables in a regression model that includes both variables. Another source of concern is the models' explanatory power. While both slope coefficients and the regressions as a whole are significant, the adjusted $R^{2}$ s from both equations are small $(<1 \%)$.

These results are somewhat in contrast to those of Scherr et al. (1993), who concentrate solely on the relation between the Celtics' game outcomes and returns. They use ANOVA analysis to test for a potential effect of win/loss/no-game on returns. The results indicate that there are differences among the three conditions, but that playoff games drive their results. During the playoffs, wins are followed by greater returns than losses, and these effects are stronger than those for the regular season. In fact, Scherr et al. argue that "regular season results are no news at all" (page 80).

\subsection{Which Games Matter?}

There is no obvious reason to expect a different market reaction (in magnitude) to good news as compared to bad news. The evidence above is consistent with the hypothesis that firm cash flows are a function of the team's on-court performance. Then, if the team performs above expectations (e.g., winning when they weren't expected to, or by more than they were expected to), this should imply a higher expected present value of the cash flows from the stock (due for example, to increases in expected ticket revenue). This should then lead to a higher market

${ }^{21}$ Scherr et al.'s analysis is incomplete for several reasons. First, they do not adjust for the market's expectations about the team's performance. If the Celtics win a game in which they are favored, there is no obvious reason to expect a price effect. Second, their methodology only differentiates between potential signals (i.e., the previous day's win or loss), and not the relative strength of the signal (i.e., by how much the team wins or loses). They also only include games played the day before the trading day, ignoring games played since the most recent trading day but before the preceding day (e.g., Saturday or Friday games). Their sample period is necessarily shorter than the one used here, possibly limiting their ability to find the proposed relations between games and returns. Scherr et al.'s paper only addresses returns, ignoring other important variables, such as volume and volatility. Finally, they do not exploit the fact that games occur when the market is closed. 
price and higher observed returns. Likewise, performing below expectations should lead to lower returns.

However, the literature does contain examples of investors giving different weight to positive and negative signals.

For example, Camerer (1989) finds evidence that in assessing the team's outlook, bettors place different weights on winning and losing streaks. They place a higher probability on losing streaks persisting compared to winning streaks; in a way, they are pessimistic. Applied here, this leads to another null hypothesis:

H3: Investors (and therefore, returns) respond symmetrically to positive and negative unexpected team performance. That is, the effect on returns should be equal in magnitude for unexpected wins and unexpected losses.

We have already seen from Table 4 some evidence against this hypothesis: Investors seem to respond differently to wins and losses (both expected and unexpected and before and after adjusting for the spread). By reformulating equations (2) and (3) to allow for differential slopes for wins and losses, we can test H3 (symmetric response). We estimate the following two equations:

$$
\begin{aligned}
\text { Abnormal Return }_{t}= & \alpha_{0}+\alpha_{1} \cdot \text { Cumulative Spread } \\
& + \\
& \alpha_{2} \cdot \text { Cumulative Spread } t \cdot \text { Loss Dummy }_{t}+\varepsilon_{t},
\end{aligned}
$$

$$
\begin{aligned}
& \text { Abnormal Return }_{t}=\beta_{0}+\beta_{1} \cdot \text { Cumulative Points }_{t}+ \\
& \beta_{2} \cdot \text { Cumulative Points } \cdot \text { Loss Dummy }{ }_{t}+\varepsilon_{t} \text {, }
\end{aligned}
$$

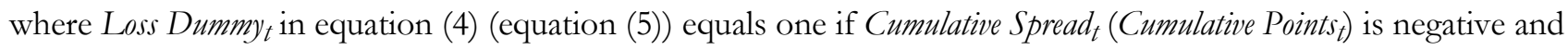
zero. Thus, these dummy variables allow for the slope coefficient of game outcomes to differ across cumulative wins and losses. 2 Columns (3) and (4) of Table 5 summarize these results. The estimated coefficients for the

\footnotetext{
${ }^{22}$ These are "cumulative" losses in the sense that Cumulative Spread (Cumulative Points) measures the total amount by which the Celtics won or lost to the spread (to opponents, ignoring the spread), since the last trading day. Over the entire weekend, for example, if the Celtics lost by more than they won, then this is counted as a cumulative loss.
} 
Cumulative Spread $d_{t}$ and Cumulative Points $t_{t}$ variables are now insignificantly different from zero (p-values of 0.154 and 0.518, respectively). In contrast, the slope coefficients for the loss dummy times the point differential variables are both significantly positive at the $1 \%$ and $5 \%$ levels, respectively, with estimated $\alpha_{2}$ equal to $3.38 \times 10^{-4}$ (p-value of 0.001) and $\beta_{2}$ equal to $2.12 \times 10^{-4}$ (p-value of 0.018$) .{ }^{23}$ These coefficients are three to four times the slope estimates in columns (1) and (2); it is apparent that losses are driving the relation. This is evidence of an asymmetric response by investors to game results: losses are penalized by much more than wins are rewarded. These findings allow us to reject the null hypothesis that the returns are symmetric. They also weakly support H2 (spreads matter): incorporating spreads into the analysis increases the loss coefficient by about 50\%, but with no real effect on adjusted Rsquareds.

As mentioned previously, one of the most immediate reasons that winning implies greater expected cash flows to investors is the increased expected playoff revenue. Playoff wins (or losses) could have a greater effect on returns than regular-season wins due to a much greater impact on the probability of future playoff games. This implies the following hypothesis:

H4: Playoff wins and losses have a greater impact on returns than regular season results.

If $\mathrm{H} 4$ is true, meaning playoffs matter more, this could have two possible implications for the previous results. First, due to their relative importance to the firm's cash flows, the playoff games may be driving the observed relations. Or, the effect of regular-season games could remain, with the playoffs having added impact. To test $\mathrm{H} 4$ and to differentiate between these two possibilities, we construct a categorical variable, Playoffs, that equals

\footnotetext{
${ }^{23}$ F-tests of the null hypothesis that $\alpha_{1}+\alpha_{2}=0$ and $\beta_{1}+\beta_{2}=0$ reject the null at the $1 \%$ level.

${ }^{24}$ As another check of this asymmetry, we model the effect due to wins and losses as differences in intercept rather than slope. These estimates, not reported here, resulted in significant negative intercepts for losses for the unadjusted differential and insignificant intercepts for the wins for either differential. This evidence is also clearly inconsistent with H3 (symmetric response). Allowing for differential slopes and intercepts (i.e., separate regressions) yielded similar results.
} 
one if there was a playoff win since the previous trading day, negative one if there was a playoff loss, and zero otherwise. This variable is then included in equations (2) through (5). These results are shown in Table 6.

[Please insert Table 6 about here]

The playoff games result in a significant effect on the following day's return, regardless of the specific equation used. The Cumulative Spread and Cumulative Points coefficients from columns (1) and (2) are only significantly different from zero at the $10 \%$ level. The Cumulative Spread coefficient is smaller $\left(6.00 \times 10^{-5}\right.$ versus the previous $\left.8.24 \times 10^{-5}\right)$, but the Cumulative Points coefficient is actually larger $\left(5.00 \times 10^{-4}\right.$ compared to the earlier $7.00 \times 10^{-}$ 5). The specifications in columns (3) and (4) generally retain their significance as reported above: positive point differentials have no positive effect on returns, but negative results do. In fact, after including the potential impact of playoffs, the coefficients on the regular-season loss variables are essentially of the same magnitude as those without the playoffs variable. The economic impact of the Playoffs coefficient in all of the specifications is larger than that implied by the coefficients in the specifications without the Playoffs variable. For example, the average margin of victory or loss against the spread is about 9 points. For a loss by this average margin, the column (3) coefficients of Table 5 imply a subsequent return of $-0.22 \%$ and the column (3) coefficients of Table 6 imply a subsequent abnormal return of $-0.20 \%$. These are less than a third of the expected incremental effect from a loss in a playoff game, $-0.64 \%$.

We therefore conclude that the playoff effect is significant above and beyond the regular-season impact of losses. This is consistent with $\mathrm{H} 4$, the prediction that playoff games matter more than regular-season games.

\footnotetext{
${ }^{25} \mathrm{We}$ used a categorical variable because the real key is whether or not the team wins and enhances its chances of advancing in the playoffs. We believe this should be more important than by how much the team wins, even if the margin of victory is used to infer the probability of future playoff wins. An alternative specification where the playoff win dummy was multiplied by the cumulative point spread difference (a slope instead of intercept effect) yielded similar results. Subsequent results using the expectation variables also support the specification used here.

${ }^{26}$ We also estimated the equations allowing the magnitude of the playoff response to vary over wins and losses. We were unable to reject the null that the return coefficient for a playoff win equals the opposite of that for a playoff loss. This could be attributable to a small sample of playoff games.
} 
Furthermore, the model specification that both incorporates the playoff variable and allows different slopes for losses increases the adjusted $R^{2}$ s of the regressions, from less than $1 \%$ in column (1) or (2) of Table 5 to about $4 \%$.

Another way of determining the importance of investor expectations is to regress returns on the expectation variables (described above and shown in Panel B of Table 4). Each trading day after a game is put into at least one category based on the expected outcome of the game(s) and the actual outcome(s) since the previous trading day. These categories result in four time series containing nonnegative integer values which represent the number of games played (since the previous trading day) that fit into each category. Four additional series are created by multiplying each series by a dummy variable that is equal to one for a trading day after a playoff game and zero otherwise. Columns (1) and (2) of Table 7 show results from regressions of Abnormal Return on these variables. For the regular season, the results are as we would expect given the previous results. Regardless of expected outcome, only actual losses (expected or unexpected) seem to have a significant impact on returns. Interpreting regression magnitudes also yields similar results to those shown in Table 4. For example, an actual loss when a win was expected results in an average $-0.4 \%$ abnormal return over the effect from covariance with the CRSP equalweighted index.

\section{[Please insert Table 7 about here]}

Inclusion of the playoff variables shows again that the regular-season results are almost unchanged after correcting for the playoffs. Surprisingly, wins seem to matter only in the playoffs. The coefficients for the playoff variables are each of the expected sign and significantly larger than the coefficients for the regular-season variables. An expected playoff win results in a positive abnormal return of about $0.9 \%$, and an unexpected playoff win yields an abnormal return of about $0.7 \%$. An unexpected loss during the playoffs implies a negative abnormal return of about $-1.1 \%$, and an expected playoff loss results in a negative abnormal return of $-0.8 \%$. Note that these returns are much more symmetric than the equivalent regular-season returns.

These effects actually appear slightly larger than one would have expected based on the cash flows directly from playoff games. As mentioned above, the average net revenue per playoff game during our sample was about 
$\$ 200,000$. Dividing this by the roughly 6 million shares outstanding during the sample implies an increase in net revenue of $\$ 0.033$ per share per playoff game. The estimated $0.8 \%$ return effect for a playoff win implies a price increase of $\$ 0.15$ using the sample average closing price of $\$ 18.55$. Thus, the returns based on our point estimates above appear a little large compared to this direct revenue effect, especially when one considers that the market should have some ex ante beliefs about the likelihood of future playoff games. Of course, the impact on other cash flows from playoff success (e.g., next season's ticket sales), error in estimating our coefficients, and the impact of one game on the likelihood of several future games being played could close the gap.

To investigate if the size of the win or loss affects these results, we multiply the expectation variables described above by the absolute value of the number of points by which the Celtics win or lose to the spread. Columns (3) and (4) of Table 7 show the results of regressing Abnormal Return on these variables. The results are very similar to those of columns (1) and (2). The only notable exception is that the coefficient on a regular season expected win is significantly negative at the $10 \%$ level. We have no explanation for this anomaly beyond random chance. Finally, adjusted $R^{2}$ s for these regressions show even more explanatory power than do those in Table 6, values range from about $2 \%$ to almost $6 \%$. Once again, we are able to reject $\mathrm{H} 3$ (symmetric response) and are unable to reject $\mathrm{H} 4$ (playoffs are more important).

This section has detailed evidence consistent with H1's alternative (games matter) and H4 (playoffs matter even more). Clearly, games contain value-relevant information that is used by investors. Playoff games contain comparatively more information than regular-season games, but do not explain the entire relation. However, the evidence is mixed with respect to $\mathrm{H} 2$ (point spreads capture the relevant expectations) and $\mathrm{H} 3$ (investors respond symmetrically to wins and losses). There is no obvious change in estimated relations when point spreads are used to capture market expectations. Investors respond asymmetrically to regular-season games but symmetrically to playoff games. The response to playoff games appears large given the direct impact of one game on revenues but is of roughly the same order of magnitude. As many of our data are atypical (e.g., the potentially large impact of discrete price changes), the Appendix discusses several checks for the robustness of the results of this section and the next section. These tests show that the above results are robust to corrections for autocorrelation in the errors, 
the possibility of non-normally distributed OLS coefficients, alternative specifications exploiting the discrete nature of price changes, and finally, alternative measures of the variables employed.

\section{The Timeliness of Information Effects}

Since games occur exclusively when the market is closed, analyzing the Celtics provides insight as to when publicly available information is embedded into stock prices. French and Roll (1986) cite the evidence of increased variance during trading hours and test hypotheses that could explain the observed pattern. They consider whether high trading-time volatility is caused by public information which is more likely to be observed during normal business hours, by private information which can only affect prices through trading when the exchanges are open, or by pricing errors (noise) that occur during trading.

Using a large sample of common stocks, French and Roll (1986) conclude that while there is evidence of mispricing, this leads to a small fraction of daily variance and explains very little of the difference between trading and non-trading variances. Differences in the information flow is then the most likely explanation. Furthermore, the authors cite evidence that most of this information is private.

While French and Roll (1986) implicitly observe closed-market volatilities, Stoll and Whaley (1990) are able to directly estimate closed-market volatilities using opening stock prices. Stoll and Whaley also find that stocks on the NYSE tend to be more volatile during the day, particularly so near the market's opening. The authors conclude that at least some component of the higher daytime volatility is due to private information revealed through trading, but most of the difference between closed-and open- market volatility is found to be due to the availability of public information.

More recently, Chang et al. (1995) found that volatility in the Standard \& Poor's 500 index futures market drops significantly after the NYSE closes, thus supporting the hypothesis that substantial volatility is contemporaneous with trading. Because it seems unlikely that there would be a big difference in the amount of publicly available information released right before the bell versus right after, we take this as further evidence that 
noise or private information is responsible for substantial volatility.

Ederington and Lee (1993) find that variations in volatility in the fixed income and foreign exchange markets is strongly related to macroeconomic news releases. After correcting for these public signals, intra-week seasonal patterns in volatility essentially disappear. Though the authors do not attempt to estimate closed-market volatilities, we interpret their results as supporting the finding of Stoll and Whaley (1990), that higher open-market volatility is mainly due to releases of publicly-available information.

Here, we add further evidence by considering a security whose relevant information flows are in direct contrast to those of the typical stock. The Boston Celtics' games represent substantial public information that is revealed during non-normal business hours. Games are played at night and over the weekend, when markets are closed. This leaves the empirical question of when and if this information is impounded into the share price. If the price-relevant information in games is a primarily objective (or public) reassessment of future cash flows or risk, then the price should adjust while the market is closed, re-opening at a new equilibrium price. If the price-relevant information is evaluated subjectively (or privately), then the price will respond as investors trade on it, which they can only do once the market is again open. This reasoning leads to the following hypothesis:

H5: If there is a private component to game-related information it will not affect prices until after the market has opened.

French and Roll (1986), Stoll and Whaley (1990), and others use ratios of multiple- to single-day volatility to test the impact of information on return variance. French and Roll (1986) construct a ratio of the variance of the return from Friday's close to Monday's close, to the average weekday close-to-close return variance. They find an average weekend-to-weekday ratio of 1.107 across all stocks in their sample; the null hypothesis of constant variance implies a weekend/weekday ratio of 3.0. Interpretation of this small ratio is difficult since it may be attributed to either (1) the reduced amount of public information released over the weekend, (2) the inability of traders to incorporate private information into stock prices while the market is closed, and/or (3) temporary mispricing caused 
by trading itself.

Compared to a typical stock, the Celtics have a much larger portion of their value-relevant public information released between Friday's close and Monday's close. This suggests that if the low weekend ratios are attributable to less public information, then the ratio should be larger for the Celtics during the season, compared to off-season. For our full-sample period, the Celtics' weekend close-to-close variance ratio is 1.35 . The on-season ratio is 1.84 , and the off-season ratio is 0.92 . This is evidence that some of the widespread low closed-market variance is due to the absence of new public information over the weekend. When such information is present, during the season, the ratio is about twice as large but still far from 3.0. This result implies that public information may account for a little more of the volatility observed in stock prices than is suggested by the French and Roll (1986) results.

Two of French and Roll's (1986) hypotheses have opposite predictions about when games will impact volatility. If high volatility is primarily a function of when public information is released, then the increased volatility due to games documented above should be reflected in the close-to-open returns. However, if as French and Roll suggest, much of the volatility associated with share prices is the result of privately informed traders who influence prices only when the market is open, then the increased volatility should be reflected in open-to-close returns on days following games. The third hypothesis considered by French and Roll, that trading itself leads to higher volatility, implies that the volatility of returns should be higher when the market is open, but not necessarily after games.

To formally test the hypothesis we construct two volatility series using daily opening and closing prices. Closed-market volatility is defined as

$$
\sigma_{t}^{c} \equiv \sqrt{506 \cdot\left[\frac{p_{t}^{o}-p_{t-1}^{c}}{p_{t-1}^{c}}\right]^{2}}
$$

where $p_{t}^{o}$ is the opening price on day $t$ and $p_{t}^{c}$ is the closing price on day $t$. Likewise, open-market volatility is 
defined as,

$$
\sigma_{t}^{o} \equiv \sqrt{506 \cdot\left[\frac{p_{t}^{c}-p_{t}^{o}}{p_{t}^{o}}\right]^{2}}
$$

We annualize by 506 since there are on average 506 total open- and closed- market periods each year during our sample. 1 We do not compare the Garman and Klass (1980) "Best" estimator for open-market volatility with the naive estimator in equation (6) for closed-market volatility because we wanted to use the same type of estimator for both sub-periods.

[Please insert Table 8 about here]

Panel A of Table 8 shows the median closed- and open-market volatilities for the full sample period.

Because a large number of the opening prices for the first half of the sample are equal to the previous closing price (about $70 \%$ through 1991), the median closed-market volatility for the full sample is equal to $0.0 \%$. It is not that surprising that a Mann-Whitney $(\mathrm{U})$ test for differences between open- and closed-market volatilities rejects the null hypothesis of no difference at the $0.1 \%$ level. Partitioning the sample into days after games were played and all other days yields similar results.

The last row of Panel A compares sub-period volatilities for trading days after games and all other days. Closed-market volatilities are not significantly higher for closed-market periods during which at least one game was played. Interestingly, open-market volatility is higher for trading periods directly following games. This suggests that, in support of $\mathrm{H} 5$, games cause investors to revise their private beliefs about the firm. These revisions lead to increased volatility the following day, as the private information is impounded into prices after the market opens.

\footnotetext{
${ }^{27}$ Note that another way of normalizing the volatilities would be to measure average hourly volatilities. The following tests were also run with these hourly estimates and without exception strengthen the significance of the results.

${ }_{28}$ Using the "Best" estimator results in higher volatility estimates than using the naive close-to-close estimator; this would result in a systematic bias toward higher relative open-market volatilities.
} 
Aside from interpreting the games' scores differently, investors could be subjectively (1) evaluating the effect of injuries or minutes played, (2) the individual performance of players, (3) how the team "looked," or (4) what the new subjective odds are of making the playoffs.

There is an obvious and troubling joint hypothesis problem in this analysis: The opening price data could simply be wrong. Because roughly $70 \%$ of opening prices prior to 1992 are the same as the previous close (and simply from bid-ask bounce we would expect about $50 \%$ to differ) this seems a valid concern. are driving this result, we obtained actual first and last daily trades for the Celtics for January 1, 1993 through May 31, 1998 from the TAQ database. Panel B shows results from the same tests using only data from 1993 through May 1998. The results are nearly identical. The median volatility for periods that include games is now slightly greater than, but not significantly different from, closed-market volatility of no-game periods. As in Panel A, returns in open-market periods following games are significantly more volatile than those for trading periods that do not follow games (at the $1 \%$ level), even though the medians are nearly identical. These results support the conclusion that investors are trading on private information (H5). They do not offer much support for the hypothesis that the timing of public information leads to the difference between open- and closed-market volatility. The difference in medians between open-market volatility and closed-market volatility for game periods is slightly less than the same difference when no game is played, and open-market volatility is significantly greater than closedmarket volatility at the $1 \%$ level. If public, rather than private, information were driving the difference in volatility, then one would expect this gap to narrow for game periods.

We can further break down investors' reaction to games by the games' expected and actual outcomes. Comparing closed- to open-market volatilities by game outcome consistently rejects the null hypothesis of equal volatility at the $1 \%$ level; open-market volatility is higher for each group (results not shown here). Panel C of Table 8 shows p-values for comparisons of periods containing (or following) games with periods not containing (or

${ }^{29}$ Opening prices were obtained from Prophet Data Services. Prophet, in turn, receives their data from Comstock, a unit of 
following) games. Regardless of game outcome, closed-market volatility is never significantly higher when games are played than when games are not played. In fact, when there is an expected win or an unexpected loss, closedmarket volatility is significantly lower than when no game is played.

The opposite is generally true for open-market periods following games. The median open-market volatility for all four game outcomes is higher than the no-game median. 5 Furthermore, unexpected wins and losses result in significantly higher volatility (at the 1\% level) on trading days following these outcomes. Because the outcomes were unexpected, these are the days we would expect to have higher volatility. These results further (strongly) support the hypothesis that investors are acting on private information after the market has opened. Furthermore, they provide additional evidence in support of H2 (i.e., it is the unexpected outcomes that should matter most) where our proxy for the expected game outcome is given by the sign of the betting-market point spread.

These conclusions are broadly consistent with the French and Roll (1986) results that high trading-time volatility is caused by private information that can only be acted upon when markets are open, and are inconsistent with the conclusion of Stoll and Whaley (1990) that public information released when the market is open is primarily responsible for higher open-market volatility. We believe that the Celtics' shares provide a very clean test of these hypotheses. While some information is revealed while the market is open (e.g., trades, details about player injuries, interviews with players and coaches), the bulk of the Celtics' value-relevant signals occur when the market is closed. In no case are closed-market volatilities higher than open-market volatilities. 11

\section{Non-Game Events}

While the above analysis addressed the impact of Celtics' games, there are many potentially interesting non-

Standard and Poors. 
game events that may also shed light on the trading patterns of the Celtics' stock. In this section, we study two important events, the collapse and rebirth of the deal for constructing the new Boston Garden, and the hiring of Rick Pitino as the Celtics' head coach.

\subsection{The New Boston Garden}

In February 1993, the deal for the construction of the new Boston Garden fell apart. Two weeks later, the deal was revived, and construction went forward later that spring. The "old" Boston Garden was no longer a stateof-the-art facility and had made it difficult for the Celtics to compete. For example, the Celtics fell from first in the league in revenues in 1984 to ninth in 1992 because "they did not have the building perks or good seats to charge top dollar" (Boston Globe, February 13, 1993, Pg. 83). In fact, the NBA was exerting pressure on the team to find a more modern place to play (Ibid.).

The owners of the old Garden agreed to build a new Garden at an estimated cost of $\$ 160$ million, a deal struck after nearly 20 years of debate over a new arena in Boston. The new arena appeared to be an attractive arrangement for the Celtics, who had negotiated a ten-year, rent-free lease. The facility would have increased luxury suites and approximately 2,000 more seats. Expost, the new Garden did prove to be more profitable. From the 1994-5 season (the last in the old Garden) to the 1995-6 season (their first in the new Garden, then named the Fleet Center), ticket revenues rose almost $60 \%$, from $\$ 22$ million to $\$ 35$ million. Game expenses, meanwhile, were actually slightly lower after the change, from $\$ 2.88$ million to $\$ 2.61$ million. Combined with a slightly lower team payroll, this lead to a jump in the Celtics' income from continuing operations from $\$ 515$ thousand in $1994-5$ to \$15.95 million in 1995-6.

Looking back, the new Garden nearly never materialized. On February 10, 1993, the Massachusetts House

30 Comparing the open-market medians for the four game-day subgroups to the median for all game days may be confusing, as all four subgroups have a higher median than the total group. However, due to multiple games over weekends and holidays, a given trading day can be counted in more than one subgroup. 
Ways and Means committee approved legislation clearing the way for construction of the new Garden. On February 11, the owner of the old Garden and developer of the new arena abruptly withdrew from the project, saying it had become "too risky" (United Press International, February 11, 1993). This announcement sent the whole arrangement (and thus the Celtics' expected cash flows) into a world of increased uncertainty. The Boston Globe reported a variety of possible outcomes, from the team relocating to spending a season or two in a makeshift arena (for example, see Boston Globe, February 13, 1993). With the impending demolition of the old Garden in 1995, the only consensus appeared to be that the current situation was untenable.

Then, on February 24, 1993, the uncertainty of the situation suddenly cleared, as a new deal was struck between the legislature and the developers. This agreement paved the way for construction to begin in June 1993. The new plan did not change the planned arena, merely the division of cash flows between the government and developers.

Based on the news accounts of these events, and with the benefit of perfect hindsight, we view the February 11 announcement as "bad news" for Celtics investors, and the subsequent reconciliation on February 24 as "good news". Of course, the collapse of the deal opened up the possibility of the Celtics obtaining an even more lucrative arrangement. However, given the strength of the Boston market for basketball, the Celtics' history there, and the attractiveness of the proposed arena and lease, we judge this unlikely. Even so, at the minimum, the deal collapse introduced substantial uncertainty over the Celtics' cash flows from 1995 forward. It also seems likely that the announcement would have produced a divergence in opinion over the eventual outcome, leading to increased trading in the Celtics' stock. Similarly, we interpret the reconciliation of February 24 as "good news" for Celtics investors. Even if investors could not foresee the strength of future cash flows, there was certainly resolution of uncertainty.

Figure 1 shows the trading activity around these dates. We present volume and stock price, but adjusting

\footnotetext{
${ }^{31}$ The Appendix also discusses several robustness checks we conducted for this section.
} 
the returns for market effects gives very similar results. 2 The observed trading pattern is not consistent with our expectations. First, volume is relatively low around the events, even compared to the on-season average of 4,876 shares. Second, price (and therefore returns) do not move as predicted: the price actually rose somewhat after the deal collapsed, and then increased only slightly after the new deal was announced $(\$ 0.25$ per share in the five days following the announcement). One possible explanation of the initial price response is that the collapse was moderately good news, possibly due to the likelihood of relocating the team to an even more profitable environment. However, if this were true, one would then expect higher volume, and a subsequent price decline when the arena was finally approved later in the month.

The only stories we can think of that are consistent with the evidence are that either (a) Celtics' investors could not foresee the effect of the stadium on firm cash flows, or (b) they never doubted that the project would be completed. Given the huge eventual impact on profitability the first of these seems unlikely (e.g., it was publicly known that in addition to the 2,000 additional seats, the new arena would have 104 lucrative executive suites compared to the old Garden's 34 boxes). Furthermore, based on the media coverage of the events (and their admitted uncertainty over the eventual outcome), the second of these stories also seems unlikely.

As a more rigorous check of this second explanation, we analyzed the trading behavior surrounding four Garden-related events leading up to February 1993, each of which indicated that the arena was incrementally closer to being built. These were the leak from City Hall that financing for a new arena seemed likely (August 30, 1991); the announcement that a new Garden would be built (May 6, 1992); the announcement of three banks that would provide financing (June 27, 1992); and the reaching of a tax accord, the "last major hurdle" (October 22, 1992). Analyzing returns of the five trading days on either side of these announcement, only events two and three had positive net returns, and they were only $0.6 \%$ (results not presented here). For the day of the announcement and the five subsequent trading days, event three returned $1.9 \%$ and event four returned $0.6 \%$; the others had zero or

\footnotetext{
32 Estimating a market model using 150 days or one year prior to February 1993 results in a very low slope coefficient $(0.06$
} 
negative returns. These magnitudes do not seem sufficient to support the hypothesis that the construction of the Garden was fully reflected in the stock price at the beginning of February 1993, and the events of that month were no news. We are at a loss, then, to explain the apparent lack of trading on the information inherent in these events.

\subsection{The Hiring of Rick Pitino}

In May 1997, the Celtics hired Rick Pitino as their new head coach. This event provides an interesting contrast to the one above. The cash flow implications were (and probably still are) much more ambiguous, but as we will show, the trading activity around the event was much more pronounced. In other words, it was and still probably is uncertain whether the hiring of Pitino was a positive net present value decision, compared to the new stadium which reasonably could only have been expected to increase the Celtics' net cash flows. Another difference was that the hiring of Pitino was expected to have both an on-the-court and financial impact, while the new arena impacted more purely the financial side of the firm. It is possible that the on-the-court, team-related nature of the announcement is what distinguishes investors' response to this event compared to the stadium-related events.

The chronology of the Pitino hiring was as follows: First, on April 30, 1997, M. L. Carr resigned as the Celtics' coach. Speculation began immediately that Larry Bird or Rick Pitino would be his successor, with a source indicating that the Celtics were prepared to offer Pitino $\$ 8-\$ 9$ million per season for five seasons, plus 3 percent of the team (Boston Globe, May 1, 1997, pg. C1). On May 1, Pitino said he would make a decision in the next week (Boston Globe, May 2, 1997, pg. E1). On May 4, Pitino met with his University of Kentucky team, saying he was going to "sleep on it" and would decide May 5 or 6 (Boston Globe, May 5, 1997, pg. D1). The same article quotes sources close to Pitino as saying that he was "leaning toward taking the Celtics job." On the night of May 5, Celtics president Red Auerbach confirmed that Pitino was taking the job, reportedly for a ten-year, $\$ 70$ million contract, but no ownership in the team (Boston Globe, May 6, 1997, pg. E1). On the afternoon of May 6, the Celtics held a press conference and officially announced the hiring of Pitino. Pitino denied that the contract was worth $\$ 70$

and 0.22 , respectively). Thus, creating abnormal returns is little more than a monotonic shift by the estimated intercept. 
million, but confirmed that it was for 10 years, six as head coach with the last four in the front office (Boston Globe, May 7, 1997, pg. C1). Over the next few days, Auerbach relinquished his title of president, and Larry Bird left his position as special assistant to be head coach of the Indiana Pacers. A confounding event to the Pitino story, the Celtics announced third-quarter 1997 earnings on May 9, which were down slightly versus the third quarter of 1996 ( $\$ 10$ million versus $\$ 10.9$ million).

After the dust had settled, the opinions on Pitino's hiring appeared to reach a consensus that it was a good basketball move, but not necessarily a good financial move. For example, analyst Peter A. Russ of Shelby Cullom Davis in New York said the short-term impact was "of negative economic value" and that he would not provide enough additional revenue opportunity to cover his salary for the next two to three years (Boston Globe, May 15, 1997, pg. C1). Stock price behavior around the hiring mimicked this chain of events: initial optimism followed by more caution.

Panel A of Figure 2 shows the volume and high, low, and closing unit prices for the Celtics during May 1997. As the figure shows, investors certainly appear to have been trading on the Pitino hiring information. Volume was high on April 30 and May 1, then skyrocketed on May 4 and May 5, to 283,000 and 87,500 shares, respectively. The unit price also rose significantly, from a close of $\$ 25.375$ on May 2 to $\$ 28.125$ on May 5 and $\$ 27.25$ on May 6. The price then drifted down, up and back down slightly, finishing May at a price of $\$ 26.50$. (For comparison, the closing price on April 1, 1997 was $\$ 24.00$.)

The price response in Panel A is much larger than the typical price response for CEO turnover. Furtado and Karan (1990) survey the corporate turnover literature; among the 10 studies they discuss, the largest average abnormal return around a turnover event is $2.48 \%$ (Bonnier and Bruner, 1989, for a group of poor-performing firms). This is dwarfed by the $7.4 \%$ return to the Celtics' shares over the comparable day -1 to day 0 period, where day 0 was the May 6 announcement date. Longer-horizon returns, while certainly suffer from potentially 
confounding events, do not eliminate this disparity. For example, over the day -5 to day +15 interval, the Celtics' shares had a cumulative return of $6.6 \%$

Based on the financial results from Pitino's first season, it is difficult to judge if this change in valuation was or was not due to an accurate forecast of increased future cash flows. Comparing the fiscal year ending June 30, 1998 (encompassing the 1997-1998 season) to fiscal 1997, the Celtics partnership had a much better year. For example, net income applicable to limited partners rose from $\$ 358$ thousand in 1997 to almost \$12 million in 1998 . The net effect of the coaching change appears to have been negligible for this first year. While ticket revenue increased almost 23\%, from $\$ 31.8$ million in 1997 to $\$ 39.1$ million in 1998 , player and coaching salaries increased by approximately $\$ 7.4$ million. This is excluding non-recurring charges in 1997 of approximately $\$ 8$ million due to changes in players and coaches (e.g., \$4.6 million in contract termination costs), which made 1998's expenses almost equal to those of 1997. Aside from the jump in ticket revenue, the increase in net income was largely attributable to a more than $20 \%$ increase in revenue from broadcast rights (from $\$ 23.3$ million to $\$ 28$ million), although most of this change was due to increased national broadcast fees, not Pitino's effect on local agreements. The net impact of the hiring of Pitino on the partnership's operating performance remains to be seen. Due to the impact of the league-wide lockout that delayed the 1998-99 season and canceled 32 games, financial results from Pitino's second season may not add much more information about his long-term effect on firm value.

Panel B of Figure 2 shows the opening and closing prices over the same period. As it shows, most of the volatility over the key days occurred while the market was open (i.e., the opening price is typically near the previous day's closing price). This is in spite of some of the information being released while the market was closed (e.g., the Globe's source story available prior to open on May 5, and Auerbach's announcement after close the same day). This is consistent with our results in Section 4, i.e., that the trading process impounds investors' private

${ }^{33}$ While we use raw returns here, these results are robust to abnormal returns. For example, using the 250 trading days prior to day -30 from the announcement, the estimated market model is not significant (based on an F-test). Furthermore, the estimated beta for the Celtics' shares is only -0.04 and not significantly different from zero. 
interpretation of a public signal.

\subsection{Summary}

In this section, we have analyzed the market response to two significant sequences of events. The first of these, the collapse of the new Boston Garden arena deal followed by the resurrection of the deal, could quite reasonably be interpreted as a "bad news" event followed by a "good news" event. The stock price response, however, was inconsistent with this story; volume never rose significantly and the unit price drifted slightly upward after both events. Ex post, the stadium was a boon for the Celtics' finances; net income rose dramatically due to increased ticket revenue while costs were relatively flat.

The second sequence of events related to the eventual hiring of Rick Pitino as the Celtics' head coach. While the net present value of this decision is an open question (in contrast to the huge positive NPV produced by the new arena), the stock price response was very large. Volume soared to about 70 times its daily average, and over the approximate month of the event, the unit price rose $\$ 2$, or $8.2 \%$.

The fact that investors responded to Pitino's hiring but not the Garden deal's ups and downs could be due to the lack of information conveyed by the arena events, or its lack of expected financial impact. However, based on the media coverage of the events and the ex post cash flow impact, neither of these explanations seems likely. An alternative explanation consistent with the data is that Celtics investors are more interested in trading on teamrelated news than non-team related news. This explanation is also more in line with the evidence that Celtics investors respond more strongly to losses than wins. However, given the evidence that game results are positively correlated with future cash flows, Celtics investors do appear to be trading on new cash-flow relevant information.

\section{Conclusion}

In this paper, we have addressed three themes. First, we analyze the impact of the Boston Celtics' games on their partnership shares. This analysis shows that investors use game results. Volume and volatility are both higher during the basketball season than during the off-season. Returns also reflect game results. However, this 
reflection is asymmetric. Losses significantly affect the stock price, but wins do not. Playoff games have an even greater impact, but the response is symmetric; playoff wins matter.

A more interesting feature of the stock market's reaction is its potential incorporation of the expected game results. If the betting market and stock markets are integrated (i.e., participants in these markets have the same expectations), then controlling for point spreads should isolate the unexpected component of the game results. However, the evidence is mixed with respect to this hypothesis. For example, even expected losses have a negative price impact and unexpected wins have no significant effect. Furthermore, in our regressions of returns on various measures of team performance, adjusting the game results for the point spread only marginally increases explanatory power. Asymmetric price response and a lack of betting/stock market integration is consistent with investors, but not bettors, always expecting the Celtics to win.

Second, we add to the literature by presenting new evidence on the impact of information on volatility. Previous research has documented that volatility is higher when the stock market is open. This research sought to attribute this finding to the timing of public information releases, private information, and/or noisy trading. Celtics games are played when the market is closed but their effect on volatility is not observed until the next time the market is open. In support of betting/stock market integration, this effect is strongest for unexpected outcomes. We interpret these findings as consistent with the private information hypothesis.

Finally, we analyze the Celtics' unit price reaction to two sequences of events. The first of these was the collapse and subsequent rescue of the deal to build a "New Boston Garden" for the team. We expected the collapse of the stadium deal to have been treated as bad news, and the subsequent rescue as good news. The Celtics unit price and trading volume, however, did not react accordingly. The second chain of events occurred around the hiring of Rick Pitino as the Celtics' head coach. Given the size of the contract, the financial impact of thee events is arguably more ambiguous. Trading on the Celtics' shares certainly responded, with very high volume around the announcement, and a net positive return over the period. While obviously a small sample, these events are consistent with investors trading more heavily on team-related than non-team-related news. 


\section{References}

Amoako-Adu, Ben, Harry Marmer, and Joseph Yagil, 1985, The Efficiency of Certain Speculative Markets and Gambler Behavior, Journal of Economics and Business 37, 365-378.

Amemiya, Takeshi, 1985, Advanced Econometrics, (Harvard University Press, Cambridge, MA).

Ball, Clifford A., 1988, Estimation Bias Induced by Discrete Security Prices, Journal of Finance 43(4), 841-865.

Barber, Brad M., and Masako N. Darrough, 1996, Product Reliability and Firm Value: The Experience of American and Japanese Automakers, 1973-1992, Journal of Political Economy 104(5), 1084-1099.

Bonnier, Karl-Adam, and Robert F. Bruner, 1989, An Analysis of Stock Price Reaction to Management Change in Distressed Firms, Journal of Accounting and Economics 11, 95-106.

Boston Globe, February 13, 1993, What's Next for Bruins, Celtics?, Pg. 83.

Boston Globe, May 1, 1997, Carr Gets Ball Rolling, Pg. C1.

Boston Globe, May 2, 1997, Pitino Will Let Us Know, Pg. E1.

Boston Globe, May 5, 1997, Pitino Leaning Toward Celtics, Pg. D1.

Boston Globe, May 6, 1997, Pitino is Primed for Celtics, Pg. E1.

Boston Globe, May 7, 1997, Pitino to be Cornerstone in Rebuilding of Celtics, Pg. C1.

Boston Globe, May 15, 1997, Amortizing a Pitino, Pg. C1.

Boston Celtics Limited Partnership and Subsidiaries, 1987-1997 Annual Reports, (Boston, MA), 1995.

Brown, Stephen, and Jerold B. Warner, 1985, Using Daily Stock Returns: The Case of Event Studies, Journal of Financial Economics 14(1), 3-31.

Brown, William, and Raymond Sauer, 1993, Fundamentals or Noise? Evidence from the Professional Basketball Betting Market, Journal of Finance 48(4), 1193-1209.

Camerer, Colin, 1989, Does the Basketball Market Believe in the 'Hot Hand'?, American Economic Review 79(5), 12571259.

Chang, Eric C., Prem C. Jain, and Peter R. Locke, 1995, Standard \& Poor's 500 Index Futures Volatility and Price Changes Around the New York Stock Exchange Close, Journal of Business 68(1), 61-84.

Dare, William H., and S. Scott McDonald, 1996, A Generalized Model for Testing the Home and Favorite Team Advantage in Point Spread Markets, Journal of Financial Economics 40(2), 295-318.

Ederington, Louis H., and Jae Ha Lee, 1993, How Markets Process Information: News Releases and Volatility, Journal of Finance 48(4), 1161-1191.

Fama, Eugene, 1976, Foundations of Finance, (University of Chicago Press, Chicago, IL).

French, Kenneth and Richard Roll, 1986, Stock Return Variances: The Arrival of Information and the Reaction of 
Traders, Journal of Financial Economics 17(1), 5-26.

Furtado, Eugene P. H., and Vijay Karan, 1990, Causes, Consequences, and Shareholder Wealth Effects of Management Turnover: A Review of the Empirical Evidence, Financial Management 19(2), 60-75.

Gandar, John, Craig R. Brown, William H. Dare, and Richard Zuber, 1998, Informed Traders and Price Variations in the Betting Market for Professional Basketball Games, Journal of Finance 53(1), 385-401.

Gandar, John, Richard Zuber, Thomas O’Brien, and Ben Russo, 1988, Testing Rationality in the Point Spread Betting Market, Journal of Finance 43(4), 995-1008.

Garman, Mark B., and Michael J. Klass, 1980, On the Estimation of Security Price Volatilities from Historical Data, Journal of Business 53(1), 67-78.

Golec, Joseph, and Murray Tamarkin, 1991, The Degree of Inefficiency in the Football Betting Market, Journal of Financial Economics 30, 311-323.

Greene, William H., 1993, Econometric Analysis, (Macmillan Publishing Co., New York, NY).

Harris, 1991, Stock Price Clustering and Discreteness, Review of Financial Studies 4(3), 389-415.

Hausman, Jerry A., Andrew W. Lo, and A. Craig MacKinlay, 1992, An ordered Probit Analysis of Transaction Stock Prices, Journal of Financial Economics 3(1), 319-379.

Jang, Hasung and Jae Ha Lee, 1995, Window Dressing of Daily Closing Bid-Ask Spreads: Evidence from NYSE Stocks, Financial Analysts Journal 51(5), 61-67.

Jones, Sally M., and Ray M. Sommerfield, 1993, Federal Taxes and Management Decisions, Richard D. Irwin, Inc., Homewood, IL.

Joy, M., R. Litzenberger, and R. McEnally, 1977, The Adjustment of Stock Prices to Announcements of Unanticipated Changes in Quarterly Earnings, Journal of Accounting Research.

Kunitomo, Naoto, 1992, Improving the Parkinson Method of Estimating Security Price Volatilities, Journal of Business 65(2), 295-302.

Livingston, Bob, 1990, 1992, 1995, The Basketball Scoreboard Book, (The Sports Weekly Newsletter, N. Charleston, SC).

Lo, Andrew W., and A. Craig MacKinlay, 1990, An Econometric Analysis of Nonsynchronous Trading, Journal of Econometrics 45(1), 181-211.

Malkiel, Burton, 1989, Efficient Market Hypothesis, in The New Palgrave Finance, (W.W. Norton and Co., New York, NY).

Parkinson, Michael, 1980, The Extreme Value Method for Estimating the Variance of the Rate of Return, Journal of Business 53(1), 61-65.

Roll, Richard, 1984, A Simple Measure of the Effective Bid-Ask Spread in an Efficient Market, Journal of Finance 39(4), 1127-1139. 
Sauer, Raymond, 1997, The Economics of Wagering Markets, Journal of Economic Literature, forthcoming.

Sauer, Raymond, Vic Brajer, Stephen Ferris, and M. Wayne Marr, 1988, Hold Your Bets: Another Look at the Efficiency of the Gambling Market for National Football League Games, Journal of Political Economy 96(1), 206-213.

Scherr, Frederick, Ashok Abbott, Mathew Thompson, 1993, Returns When Signals of Value Are Frequent: The Boston Celtics, Journal of Business and Economic Studies 2(1), 69-83.

Stoll, Hans R., and Robert E. Whaley, 1990, Stock Market Structure and Volatility, Review of Financial Studies 3(1), $37-$ 71.

United Press International, February 11, 1993, Developer Pulls Out of Boston Garden Project.

Zuber, Richard A., John M. Gandar, and Benny D. Bowers, 1985, Beating the Spread: Testing the Efficiency of the Gambling Market for National Football League Games, Journal of Political Economy 93, 800-806. 


\section{Appendix: Robustness of the Results}

Prior research on daily stock returns has documented several properties that make us question the applicability of OLS regression methods and the assumption of normally distributed errors for inference. For example, Fama (1976, ch. 1) and Brown and Warner (1985) describe the leptokurtic nature of daily returns and abnormal returns. Lo and MacKinlay (1990) and Roll (1984) model and test autocorrelation in daily returns. Hausman, Lo and MacKinlay (1992), Harris (1991), Ball (1988), and others investigate the discrete nature of individual stock prices changes. Each of these findings could imply that our models are misspecified or that the inference is incorrect. To determine if any of these potential problems are driving our results, we conduct a series of robustness checks on our results. These checks include several alternative specifications of our models and bootstrapping the distribution of estimated coefficients.

Perhaps the most obvious potential problem is autocorrelated errors. Estimating a simple market model but allowing for serially correlated errors results in a significant first order autocorrelation coefficient of -0.060 ( $p$ value $=0.000)$. Box-Jenkins analysis of the residuals from this model is unable to reject the null of white-noise (out to 10 lags) at the $1 \%$ level. To determine if this small, but highly significant, autocorrelation has any affect on our

results, we rerun all of the regressions in Tables 4, 5, and 6 using the residuals from this AR(1) market model. 2.4 The results are extremely similar to those reported. Both coefficient estimates and significance levels are essentially unchanged. No qualitative change in the interpretation of the results is necessary and only one coefficient changes significance group (e.g., $1 \%$ to $5 \%$ significance level). 5 As we would expect a priori, if the source of autocorrelation is random bid-ask bounce, the bounce effect should be orthogonal to the effects we are measuring.

The next source of concern is the likely non-normal distribution of the residuals. For example, the empirical distribution of the errors for the model estimated in column (1) of Table 5 has a skewness of 1.19 and

\footnotetext{
${ }^{34}$ Since we suspect the autocorrelation to be the results of bid-ask bounce, an MA(1) specification seems an attractive alternative. Use of residuals from an MA(1) model also has little effect on the results.
} 
kurtosis of 8.89.6 A Wald test for normality yields a chi-squared statistic of 1,305.2, indicating that the null hypothesis of normally distributed errors can be rejected at the $1 \%$ level. ${ }^{b}$ Consequently, inference assuming normally distributed errors may be significantly and systematically biased. The empirical distribution and associated p-values for each of the coefficients in Tables 5, 6, and 7 are estimated using simple OLS bootstrapping techniques. 6.8 Without exception, each of the reported coefficients remains in the same significance group or increases in significance. We also estimate the models using the method of maximum likelihood and the assumption of logistically distributed errors. This method yields coefficient estimates of similar magnitude but with smaller standard errors (which yield smaller p-values).

Another concern is the discrete nature of price changes. Over our sample the share price ranged from a minimum of $\$ 10.625$ to a maximum of $\$ 28.125$. The smallest allowed price change (the tick size) is $\$ 0.125$, so using the maximum share price yields a smallest nonzero return of about $0.4 \%$, much larger than the average daily return and roughly the same size as the effects we are describing. Furthermore, for the full sample, $86 \%$ of the daily price changes were $-2,-1,0,1$, or 2 ticks. It may be that the assumption of continuous prices and errors are inappropriate in this setting.

To test for the effects of games in a discrete price setting, we employ the Hausman, Lo, and MacKinlay (1992) ordered probit model with the assumption of homoskedastic errors. We allow for discrete price (tick) changes in the set $\{\leq-4,-3, . ., 3, \geq 4\}$. We augment the models in Tables 5,6 , and 7 by including market returns and using all days in the sample period. This allows us to estimate the market and game effects in one step. Results of this alternative estimation technique are qualitatively unchanged from those above that relied on the assumption of continuous returns. In Tables 5-7, 10 of the of the 32 significant coefficients increase in significance level; none

\footnotetext{
${ }^{35}$ The coefficient $E[$ Loss]:Loss in column (1) of Table 7 changed from being significant at the $5 \%$ level to the $1 \%$ level. ${ }^{36}$ These values are very similar to those reported by Brown and Warner $(1985, \mathrm{pg}$. 9) for a large sample of individual common stocks.

${ }^{37}$ See Greene (1993), pp. 309-310.

${ }^{38}$ See Amemiya (1985), pp. 135.
} 
decrease. Two coefficients that are not significant in the earlier regressions now are: (1) the coefficient on Cumulative Spread in the third column of Tables 5 and 6 becomes significantly negative at the $5 \%$ level, and (2) the coefficient on E[Win]:Win in the third column of Table 7 becomes significant at the $10 \%$ level.

While the discrete price-change models seems to fit the data better, we present the continuous-variable results above because the coefficients can be more easily interpreted. That our inference (i.e., the significance and sign of the important coefficients) does not change in any meaningful way under the ordered probit models gives us more confidence in the results of Tables 4, 5, and 6. Two other discrete price change models yielded similar results.

As noted in the previous section, our data for opening prices may be wrong. These opening prices are used in the Garman and Klass (1980) "Best" estimates of volatility reported in Table 2. To insure that these prices do not bias our results, we also calculate volatility using a simple close-to-close estimator (similar to equation (6)), the Parkinson (1980) extreme value method (which uses only high and low prices), and the Kunitomo (1992) extreme value method (a refinement of Parkinson's). All of these estimators yield similar qualitative results, but with lower significance levels. This is as we expect since each of these estimators is theoretically less powerful than the Garman and Klass (1980) "Best" estimator. Infrequently traded stocks tend to have their volatility overestimated using the "Best" estimator, and Garman and Klass (1980) derive a correction based on the number of daily trades. Because we only have the number of trades for 1993 and 1998 (from the TAQ database), we estimate the corrected volatility series for these observations. We also divide daily volume by average trade size to get an estimate of the number of daily trades for the full sample. Use of these "corrected" volatility series also leads to qualitatively similar

\footnotetext{
${ }^{39}$ On June 24, 1997 the NYSE started trading with a tick size of one sixteenth of a dollar. The subsequent analysis uses data before this date.

${ }^{40}$ The first assumes a binomial distribution to price changes and restricts the maximum number of up or down moves. The probability of an up move is parameterized as the inverse of the cumulative normal function of a linear specification of independent variables (much like a probit). The second is a Poisson hurdle model. We model the absolute price change in number of ticks. These models are estimated using maximum likelihood for parameterizations designed to capture similar effects as those in Tables 4, 5, and 6 . The results are qualitatively very similar to those reported, but significance of estimated coefficients depends on the maximum allowed tick size for the binomial model and the set of hurdle factors used
} 
interpretations and inference of results presented in Table 3.

There is no possible way to eliminate the potential influences of bid-ask bounce in the estimates of closedand open-market volatility presented in Table 8 if we limit ourselves to transaction data. The next-best alternative is to use closing and opening quotes. These quotes are available for 1993 and 1998 on the TAQ database. The final daily quote before 4:00pm EST and the first new quote after 9:45am EST are recorded for each day. estimates of closed- and open- market volatility are then obtained by using (1) the bid prices, (2) ask prices, and (3) the average of the bid and ask prices. Each of these methods results in nearly identical results to those presented in Panels B and C of Table 8. Using closing quotes may also introduce a bias since Jang and Lee (1995) found that, "NYSE specialists appear to reduce bid-ask spreads sharply at the market close and report them to the exchange solely for the purpose of window dressing." Since the effect is mainly in bid prices, and the results of our analysis appear to be independent of which measure of closing price we use, we conclude that this effect is not driving our results.

In conclusion, we are very confident that the previously reported relations are not the result of model misspecification, poor data, or other potentially systematic estimation errors. The corrections for autocorrelation, non-normally distributed errors, discreteness of prices, and the use of alternative estimators do not appreciably change the inference conducted in Sections 3 and 4.

in the Poisson hurdle model.

${ }^{41}$ We wait until after 9:45 to eliminate any opening-auction effects (if this produces a bias it should work against our results). For example, Jang and Lee (1995) find that the opening spread is systematically the widest of the day. 


\section{Table 1}

\section{Descriptive Statistics}

This table details mean daily returns, mean average annual returns, and the number of observations for both the Boston Celtics LP and the CRSP market indices over the January 1, 1987 to May 31, 1998 sample period. The Celtics' actual win-loss record, as well as their record against the spread over this period are also presented.

\begin{tabular}{|l|c|c|c|}
\cline { 2 - 4 } \multicolumn{1}{l|}{} & $\begin{array}{c}\text { Mean Daily } \\
\text { Return }\end{array}$ & $\begin{array}{c}\text { Mean Annual } \\
\text { Return }\end{array}$ & $\begin{array}{c}\text { Number of } \\
\text { Observations }\end{array}$ \\
\hline Full Sample: & $0.044 \%$ & $11.7 \%$ & \\
Celtics Limited Partnership & $0.053 \%$ & $14.2 \%$ & 2884 \\
CRSP Equal-Weighted Index & $0.060 \%$ & $16.4 \%$ & \\
CRSP Value-Weighted Index & & & \\
Off-Season Only: & $0.08 \%$ & $21.50 \%$ & \\
Celtics Limited Partnership & $-0.01 \%$ & $-1.85 \%$ & \\
CRSP Equal-Weighted Index & $0.02 \%$ & $4.35 \%$ & \\
CRSP Value-Weighted Index & & & \\
On-Season Only: & & & \\
Celtics Limited Partnership & $0.02 \%$ & $5.54 \%$ & \\
CRSP Equal-Weighted Index & $0.09 \%$ & $26.40 \%$ & \\
CRSP Value-Weighted Index & $0.09 \%$ & $25.23 \%$ & \\
Post Game-Days Only: & & & \\
Celtics Limited Partnership & & & \\
CRSP Equal-Weighted Index & $-0.052 \%$ & $-11.0 \%$ & \\
CRSP Value-Weighted Index & $0.072 \%$ & $18.7 \%$ & \\
\hline
\end{tabular}

\begin{tabular}{|l|c|c|c|}
\cline { 2 - 4 } \multicolumn{1}{c|}{} & Wins & Losses & Total Games \\
\hline Win-Loss Record & 533 & 499 & 1032 \\
Win-Loss Record vs. Spread* & 498 & 499 & 997 \\
\hline
\end{tabular}

* Total Games is less for Record vs. Spread because of ties which are not allowed as an actual game result and missing spreads. 
Table 2

\section{Franchise Value, Operating Income, and Winning}

This table presents results of regressions of team value and income on team performance. Columns one and two present random effects regressions for all teams in the NBA, NFL, and Major League baseball for the 1991-1997 period. Dummy variables for each sport-year were included in the regressions but are not presented. Franchise Value and Operating Income are in millions of dollars and are from Financial World's estimates. Columns three and four are for the Boston Celtics LP only. The dependent variables are the change in net revenue from basketball-related operations of the LP (e.g., they exclude discontinued operations, interest expense and taxes). Column three's dependent variable is on a per share basis and excludes any playoff revenues or expenses.

Column four's dependent variable is in dollars and includes the net effect of the playoffs. Stadium Change is a dummy variable set to one in the year the Celtics moved from the Boston Garden to the Fleet Center and zero otherwise. One, two, and three asterisks denote significance at the $0.10,0.05$, and 0.01 levels, respectively.

\begin{tabular}{|c|c|c|c|c|}
\hline & \multicolumn{2}{|c|}{ Three Major Sports } & \multicolumn{2}{|c|}{ Celtics Only } \\
\hline & $\begin{array}{r}\text { Franchise } \\
\text { Value }_{t} \\
(1) \\
\end{array}$ & $\begin{array}{l}\text { Operating }^{\text {Income }}{ }_{t} \\
(2) \\
\end{array}$ & $\begin{array}{c}\Delta \text { Basketball Revenue } \\
\text { Per Share }_{t} \\
\text { (excludes playoffs) } \\
(3)\end{array}$ & $\begin{array}{c}\Delta \text { Basketball Revenue } \\
\text { (includes playoffs) } \\
(4)\end{array}$ \\
\hline Constant & $\begin{array}{l}104.45 \\
(0.000) * * * \\
\end{array}$ & $\begin{array}{c}3.88 \\
(0.056) * \\
\end{array}$ & $\begin{array}{l}-3.072 \\
(0.011) * *\end{array}$ & $\begin{array}{r}-16,177,571 \\
(0.029) * *\end{array}$ \\
\hline Winning Percentage $_{t}$ & $\begin{array}{r}8.16 \\
(0.172) \\
\end{array}$ & $\begin{array}{r}-0.08 \\
(0.970) \\
\end{array}$ & & \\
\hline Winning Percentage $_{t-1}$ & $\begin{array}{c}26.20 \\
(0.000) * * * \\
\end{array}$ & $\begin{array}{c}7.37 \\
(0.001) * * * \\
\end{array}$ & & \\
\hline Number of Wins $_{t-1}$ & & & $\begin{array}{c}0.057 \\
(0.018) * *\end{array}$ & $\begin{array}{l}289,502 \\
(0.048) * *\end{array}$ \\
\hline Stadium Change & & & $\begin{array}{c}0.033 \\
(0.001) * * *\end{array}$ & $\begin{array}{r}17,817,321 \\
(0.003) * * *\end{array}$ \\
\hline \begin{tabular}{|l|} 
Number of Teams \\
Number of Observations \\
R-Squared
\end{tabular} & $\begin{array}{r}85 \\
575 \\
0.583 \\
\end{array}$ & $\begin{array}{r}85 \\
575 \\
0.229 \\
\end{array}$ & $\begin{array}{r}1 \\
10 \\
0.817 \\
\end{array}$ & $\begin{array}{r}1 \\
10 \\
0.749 \\
\end{array}$ \\
\hline
\end{tabular}


Table 3

\section{Volume and Volatility Statistics}

This table presents the mean daily trading volume and return volatility over the full sample period (January 1, 1987 to May 31, 1998) for the unit shares of the Boston Celtics LP. P-values from MannWhitney (U) tests for the differences in these variables between off-season and on-season and between days that follow games and do not follow games are also presented. Volatility is calculated using the Garman and Klass (1980) "Best" estimator.

\begin{tabular}{|c|c|c|}
\hline & Mean & p-value \\
\hline Daily Trading Volume & 4423 & \\
\hline \multirow{2}{*}{$\begin{array}{l}\text { Off-Season } \\
\text { On-Season }\end{array}$} & \multirow{2}{*}{$\begin{array}{l}3856 \\
4876\end{array}$} & On $>$ Off \\
\hline & & 0.000 \\
\hline \multirow{4}{*}{$\begin{array}{l}\text { No Game Since Last Trading Day } \\
\text { Game Since Last Trading Day } \\
\text { No Game Since Last Trading Day (Season Only) } \\
\text { Game Since Last Trading Day }\end{array}$} & \multirow{2}{*}{$\begin{array}{l}4043 \\
5419\end{array}$} & Game $>$ No Game \\
\hline & & 0.011 \\
\hline & \multirow{2}{*}{$\begin{array}{l}4341 \\
5419\end{array}$} & \multirow{2}{*}{$\frac{\text { Game }>\text { No Game }}{0.026}$} \\
\hline & & \\
\hline Daily Return Volatility (annualized) & \multicolumn{2}{|l|}{$15.38 \%$} \\
\hline \multirow{2}{*}{$\begin{array}{l}\text { Off-Season } \\
\text { On-Season }\end{array}$} & \multirow{2}{*}{$\begin{array}{l}14.93 \% \\
15.74 \%\end{array}$} & On $>$ Off \\
\hline & & 0.000 \\
\hline \multirow{2}{*}{$\begin{array}{l}\text { No Game Since Last Trading Day } \\
\text { Game Since Last Trading Day }\end{array}$} & \multirow{2}{*}{$\begin{array}{l}15.06 \% \\
16.22 \%\end{array}$} & Game > No Game \\
\hline & & 0.014 \\
\hline \multirow{2}{*}{$\begin{array}{l}\text { No Game Since Last Trading Day (Season Only) } \\
\text { Game Since Last Trading Day }\end{array}$} & \multirow{2}{*}{$\begin{array}{l}15.26 \% \\
16.22 \% \\
\end{array}$} & Game > No Game \\
\hline & & 0.032 \\
\hline
\end{tabular}


Table 4

\section{Mean Abnormal Returns}

This table details mean abnormal returns for the Boston Celtics LP over the January 1, 1987 to May 31, 1998 sample period. Panel A shows post-game day abnormal returns by game outcome. Abnormal returns are defined as the residuals from a market-model regression of the Celtics' return on the CRSP equal-weighted index return. Categories are defined by unadjusted game outcome spread adjusted outcome pairs. For example, Win : Loss indicates that the Celtics won the game but lost against the spread. The number of games in each category and p-values for two-tailed tests comparing each mean against the null hypothesis of mean equal tc zero are presented below each value. Equivalent mean p-values for mean pairs are also noted below. Panel B details mean abnormal returns based on expected game outcome - actual game outcome pairs. For example, E[Win]:Loss indicates that the spread was negative and the Celtics lost the game. The number of games in each category and p-values for two-tailed tests comparing each mean against the null hypothesis of mean equal to zero are presented below each value. Equivalent mean p-values for mean pairs are also noted below. (Means tests assume normally distributed abnormal returns.) For post game days when multiple games have been played since the last trading day, category is determined by aggregated data (i.e., summed across games) for Panel A and by any outcome fitting the appropriate catagory for Panel B.

Panel A

Mean Post-Game Day Abnormal Returns

\begin{tabular}{|c|c|c|c|c|c|}
\hline & \multicolumn{4}{|c|}{ Unadjusted Game Outcome : Outcome Against Spread } \\
\hline & & Win : Win & Win : Loss & Loss : Win & Loss : Loss \\
\hline \multirow{3}{*}{\multicolumn{2}{|c|}{$\begin{array}{l}\text { Mean Post-Game Return } \\
\text { Observations } \\
\text { p-value: Mean =0 }\end{array}$}} & $0.054 \%$ & $0.305 \%$ & $-0.001 \%$ & $-0.229 \%$ \\
\hline & & 314 & 87 & 76 & 285 \\
\hline & & 0.214 & 0.016 & 0.110 & 0.002 \\
\hline \multirow[t]{4}{*}{ Difference in Mean } & \multirow{4}{*}{$\begin{array}{l}\text { Win : Win } \\
\text { Win : Loss } \\
\text { Loss : Win }\end{array}$} & & & p-values & \\
\hline & & & \multirow[t]{3}{*}{0.056} & 0.072 & 0.003 \\
\hline & & & & 0.007 & 0.001 \\
\hline & & & & & 0.207 \\
\hline
\end{tabular}

Panel B

Mean Post-Game Day Abnormal Returns Conditioned on Expectations and Game Outcome

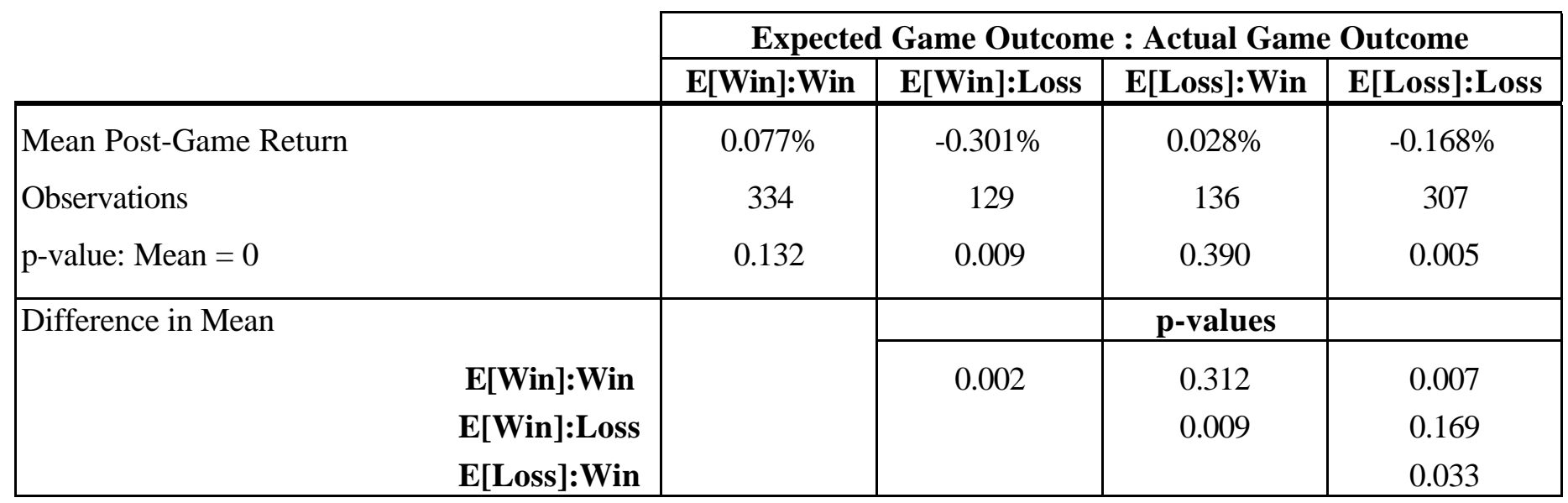


Table 5

\section{Regressions of Market-Adjusted Returns on Game Result Variables Dependent Variable: Abnormal Return}

This table reports results of OLS regressions of abnormal returns (using the CRSP equal-weight index) on both winloss point differentials and spread adjusted win-loss point differentials. Variables are defined below. The regressions encompass the sample period from January 1, 1987 to May 31, 1998. P-values are shown below coefficients. Abnormal Return is defined as the residual from a market model regression of the daily Celtics return on the CRSP equal-weighted index return. Cumulative Spread is defined as the cumlative points by which the Celtics beat (lost to) the spread since the last trading day. Cumulative Points is defined as the cumlative points by which the Celtics won (lost) since the last trading day. One, two, and three asterisks denote significance at the $0.10,0.05$, and 0.01 levels, respectively.

\begin{tabular}{|l|c|c|c|c|}
\cline { 2 - 5 } \multicolumn{1}{c|}{} & $(1)$ & $(2)$ & $(3)$ & $(4)$ \\
\hline Constant & $\begin{array}{r}-0.00106 \\
(0.017) * *\end{array}$ & $\begin{array}{r}-0.00110 \\
(0.013) * *\end{array}$ & $\begin{array}{r}0.00066 \\
(0.341)\end{array}$ & $\begin{array}{r}0.00028 \\
(0.390)\end{array}$ \\
\hline Cumulative Spread & $\begin{array}{r}8.24 \mathrm{E}-05 \\
(0.014) * *\end{array}$ & & $\begin{array}{r}-9.00 \mathrm{E}-05 \\
(0.154)\end{array}$ & \\
\hline Cumulative Points & & $7.00 \mathrm{E}-05$ & & $-3.30 \mathrm{E}-05$ \\
$(0.009) * * *$ & & $(0.518)$ \\
\hline $\begin{array}{l}\text { Cumulative Spread } \\
* \text { Loss Dummy }\end{array}$ & & & $3.38 \mathrm{E}-04$ & \\
\hline $\begin{array}{l}\text { Cumulative Points } \\
* \text { Loss Dummy }\end{array}$ & & & & \\
\hline Observations & & & $79.001) * * *$ & $2.12 \mathrm{E}-04$ \\
\hline Adj. R-Squared & 0.008 & 0.009 & 0.021 & $0.018 * *$ \\
\hline
\end{tabular}


Table 6

\title{
Regressions of Market-Adjusted Returns on Game Result Variables Including Playoff Variable \\ Dependent Variable: Abnormal Return
}

\begin{abstract}
This table reports results of OLS regressions of abnormal returns (using the CRSP equal-weight index) on both win-loss point differentials and spread adjusted win-loss point differentials, including a variable for playoff games. The regressions encompass the sample period from January 1, 1987 to May 31, 1998. P-values are shown below coefficients. Abnormal Return is defined as the residual from a market model regression of the daily Celtics return on the CRSP equal-weighted index return. Cumulative Spread is defined as the cumlative points by which the Celtics beat (lost to) the spread since the last trading day. Cumulative Points is defined as the cumlative points by which the Celtics won (lost) since the last trading day. The Loss Dummy variable is defined as equal to one when the independent variable associated with the loss dummy is less than zero and zero otherwise. Playoffs is a categorical variable equal to one if the Celtics won a playoff game during the previous day, negative one if they lost, and zero otherwise. One, two, and three asterisks denote significance at the $0.10,0.05$, and 0.01 levels, respectively.
\end{abstract}

\begin{tabular}{|l|c|c|c|c|}
\cline { 2 - 5 } \multicolumn{1}{c|}{} & $(1)$ & $(2)$ & $(3)$ & $(4)$ \\
\hline Constant & -0.00102 & -0.00105 & 0.00063 & 0.00027 \\
& $(0.020) * *$ & $(0.016) * *$ & $(0.356)$ & $(0.707)$ \\
\hline Cumulative Spread & $6.00 \mathrm{E}-05$ & & $-1.07 \mathrm{E}-04$ & \\
& $(0.077) *$ & & $(0.090) *$ & \\
\hline Cumulative Points & & $5.00 \mathrm{E}-04$ & & $-4.90 \mathrm{E}-05$ \\
& & $(0.069) *$ & & $(0.333)$ \\
\hline Cumulative Spread & & & $3.26 \mathrm{E}-04$ & \\
$*$ Loss Dummy & & & $(0.002) * * *$ & \\
\hline Cumulative Points & & & & $2.04 \mathrm{E}-04$ \\
$*$ Loss Dummy & & & & $(0.002) * * *$ \\
\hline Playoffs & $6.52 \mathrm{E}-03$ & $6.44 \mathrm{E}-03$ & $6.39 \mathrm{E}-03$ & $6.34 \mathrm{E}-03$ \\
& $(0.000) * * *$ & $(0.000) * *$ & $(0.000) * * *$ & $(0.000) * * *$ \\
\hline Observations & 793 & 793 & 793 & 793 \\
\hline Adj. R-Squared & 0.028 & 0.029 & 0.041 & 0.035 \\
\hline
\end{tabular}


Table 7

\title{
Regressions of Market-Adjusted Returns on Game Result Variables
}

\author{
Dependent Variable: Abnormal Return
}

This table reports results of OLS regressions of abnormal returns (using the CRSP equal-weight index) on all possible pairs of expected and actual game results. For example, E[Win]:Loss denotes the number of games since the last market close for which there was a negative spread and a loss by the Celtics. Column (1) shows the regression on these four variables. Column (2) includes the same variables plus these variables for the playoffs only. Columns (3) and (4) repeat the procedure but to capture size effects of wins/losses, the independent variables are multiplied by the absolute value of the number of points by which the Celtics beat or lost to the spread. The regressions encompass the sample period from January 1, 1987 to May 31, 1998. Pvalues are shown below coefficients. One, two, and three asterisks denote significance at the $0.10,0.05$, and 0.01 levels, respectively.

\begin{tabular}{|l|c|c|c|c|}
\cline { 2 - 5 } \multicolumn{1}{c|}{} & \multicolumn{2}{c|}{ Number of Games Only } & \multicolumn{2}{c|}{ Number of Games x Points } \\
\cline { 2 - 5 } & $(1)$ & $(2)$ & $(3)$ & $(4)$ \\
\hline Constant & 0.00060 & 0.00066 & 0.00057 & 0.00048 \\
& $(0.608)$ & $(0.569)$ & $(0.345)$ & $(0.421)$ \\
\hline E[Win]:Win & 0.00013 & -0.00061 & -0.00005 & -0.00009 \\
& $(0.902)$ & $(0.551)$ & $(0.338)$ & $(0.089) *$ \\
\hline E[Win]:Loss & -0.00382 & -0.00295 & -0.00017 & -0.00012 \\
& $(0.003) * * *$ & $(0.022) * *$ & $(0.002) * * *$ & $(0.045) * *$ \\
\hline E[Loss]:Win & -0.00021 & -0.00060 & -0.00005 & -0.00005 \\
& $(0.872)$ & $(0.647)$ & $(0.458)$ & $(0.419)$ \\
\hline E[Loss]:Loss & -0.00235 & -0.00211 & -0.00020 & -0.00019 \\
& $(0.021) * *$ & $(0.038) * *$ & $(0.000) * * *$ & $(0.001) * * *$ \\
\hline E[Win]:Win & & 0.00984 & & 0.00073 \\
$*$ Playoff Dummy & & $(0.000) * * *$ & & $(0.000) * * *$ \\
\hline E[Win]:Loss & & -0.00839 & & -0.00031 \\
$*$ Playoff Dummy & & $(0.010) * * *$ & & $(0.025) * *$ \\
\hline E[Loss]:Win & & 0.00772 & & 0.00025 \\
$*$ Playoff Dummy & & $(0.069) *$ & & $(0.325)$ \\
\hline E[Loss]:Loss & & -0.00579 & & -0.00023 \\
*Playoff Dummy & & $(0.014) * *$ & & $(0.131)$ \\
\hline Observations & & 793 & & 793 \\
\hline Adj. R-Squared & 0.022 & 0.058 & & 0.056 \\
\hline
\end{tabular}


Table 8

\section{Closed-Market and Open-Market Price Volatility}

This table presents the median price volatility over two sample periods for the Boston Celtics LP for times when the market is closed and open. The sample is broken into two groups based on whether a game was played since the last trading day. Volatilities for closedand open-market periods are calculated from closing and opening prices. P-values for Mann-Whitney (U) tests for the differences between closed-market and open-market volatility, and between volatility for periods that follow games and do not follow games are also presented. Panel A shows results from the full sample period (January 1, 1987 to May 31, 1998). Because opening prices for approximately the first four years of the sample are usually the same as previous closing prices, the median closed-market volatilities are zero percent. Panel B shows the same statistics for the sub-period January 1, 1993 to May 31, 1998. These data for Panel B were obtained from the TAQ database and are deemed more reliable (see text). Panel C compares volatilites based on expected and actual game outcomes for 1993-1998. In addition to presenting the median volatility, the volatiltity for each subgroup is compared to the volatility when the market was closed or open, and no game was played. For example, the (upper-left) Closed-Market E[Win]:Win cell presents median volatility for times when the market is closed and the celtics have an expected win. The asterisks represent significance of tests of equal volatility over these periods compared to all periods when the market is closed and no games are played. P-values (not shown in Panel C) are obtained using the Mann-Whitney (U) test. One, two, and three asterisks denote significance at the $0.10,0.05$, and 0.01 levels, respectively.

\section{Panel A: Full Sample}

\begin{tabular}{|c|c|c|c|c|}
\hline \begin{tabular}{|l} 
Median Price Volatility \\
(annualized)
\end{tabular} & $\begin{array}{c}\text { Number of } \\
\text { Observations } \\
\end{array}$ & $\begin{array}{l}\text { Closed- } \\
\text { Market } \\
\end{array}$ & $\begin{array}{c}\text { Open- } \\
\text { Market }\end{array}$ & $\begin{array}{c}\text { p-value } \\
\text { Open > Closed }\end{array}$ \\
\hline All Trading Days & 2,884 & $0.00 \%$ & $14.66 \%$ & $0.000 * * *$ \\
\hline $\begin{array}{l}\text { No Game Since Last Trading Day } \\
\text { Game Since Last Trading Day }\end{array}$ & $\begin{array}{c}2,091 \\
793\end{array}$ & $\begin{array}{l}0.00 \% \\
0.00 \%\end{array}$ & $\begin{array}{l}14.15 \% \\
15.74 \%\end{array}$ & $\begin{array}{l}0.000 * * * \\
0.000 * * *\end{array}$ \\
\hline p-value: Game > No Game & & 0.443 & $0.027 * *$ & \\
\hline
\end{tabular}

Panel B: 1993-1998

\begin{tabular}{|l|c|cc|r|}
\hline $\begin{array}{l}\text { Median Price Volatility } \\
\text { (annualized) }\end{array}$ & $\begin{array}{c}\text { Number of } \\
\text { Observations }\end{array}$ & $\begin{array}{c}\text { Closed- } \\
\text { Market }\end{array}$ & $\begin{array}{c}\text { Open- } \\
\text { Market }\end{array}$ & $\begin{array}{c}\text { p-value } \\
\text { Open > Closed }\end{array}$ \\
\hline All Trading Days & 1366 & $11.96 \%$ & $13.35 \%$ & $0.007 * * *$ \\
\hline No Game Since Last Trading Day & 1008 & $11.89 \%$ & $13.31 \%$ & $0.004 * * *$ \\
Game Since Last Trading Day & 358 & $12.02 \%$ & $13.39 \%$ & $0.000 * * *$ \\
\hline p-value: Game > No Game & & 0.487 & $0.000 * * *$ & \\
\hline
\end{tabular}

Panel C: Median Volatility by Expected and Actual Outcome (1993-1998)

\begin{tabular}{|l|c|c|c|c|c|}
\hline Market Sub-Period & No Game & E[Win]:Win & E[Win]:Loss & E[Loss]:Win & E[Loss]:Loss \\
\hline Closed-Market & $11.89 \%$ & $9.37 \% * * *$ & $10.50 \% * * *$ & $12.15 \%$ & $12.22 \%$ \\
Open-Market & $13.31 \%$ & $13.68 \%$ & $15.11 \% * * *$ & $14.33 \% * * *$ & $13.39 \%$ \\
\hline
\end{tabular}


Figure 1

\section{Stock Price and Volume Around Garden Event}

Celtics' unit price and volume around "New" Boston Garden announcements of February 1993. The stock prices shown are closing prices, and volume is shown in shares.

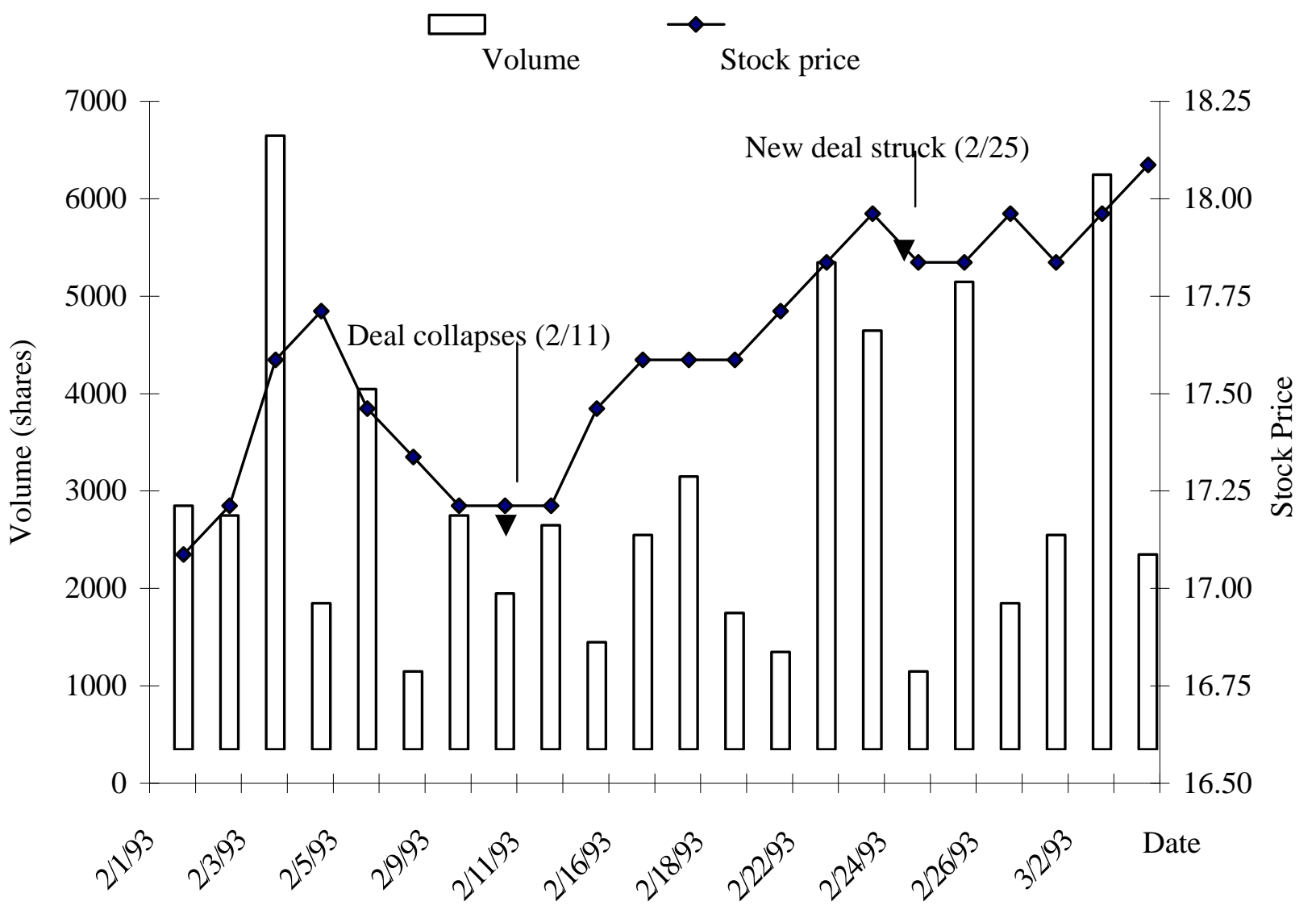


Figure 2

\section{Stock Price and Volume Around the Hiring of Rick Pitino}

Panel A shows daily volume and the unit price's daily high, low, and closing values for May 1997. Panel B shows the opening and closing prices for each day. The official announcement of Risk Pitino's hiring occurred on May 5.

\section{Panel A: Pitino Hiring Trading Activity}

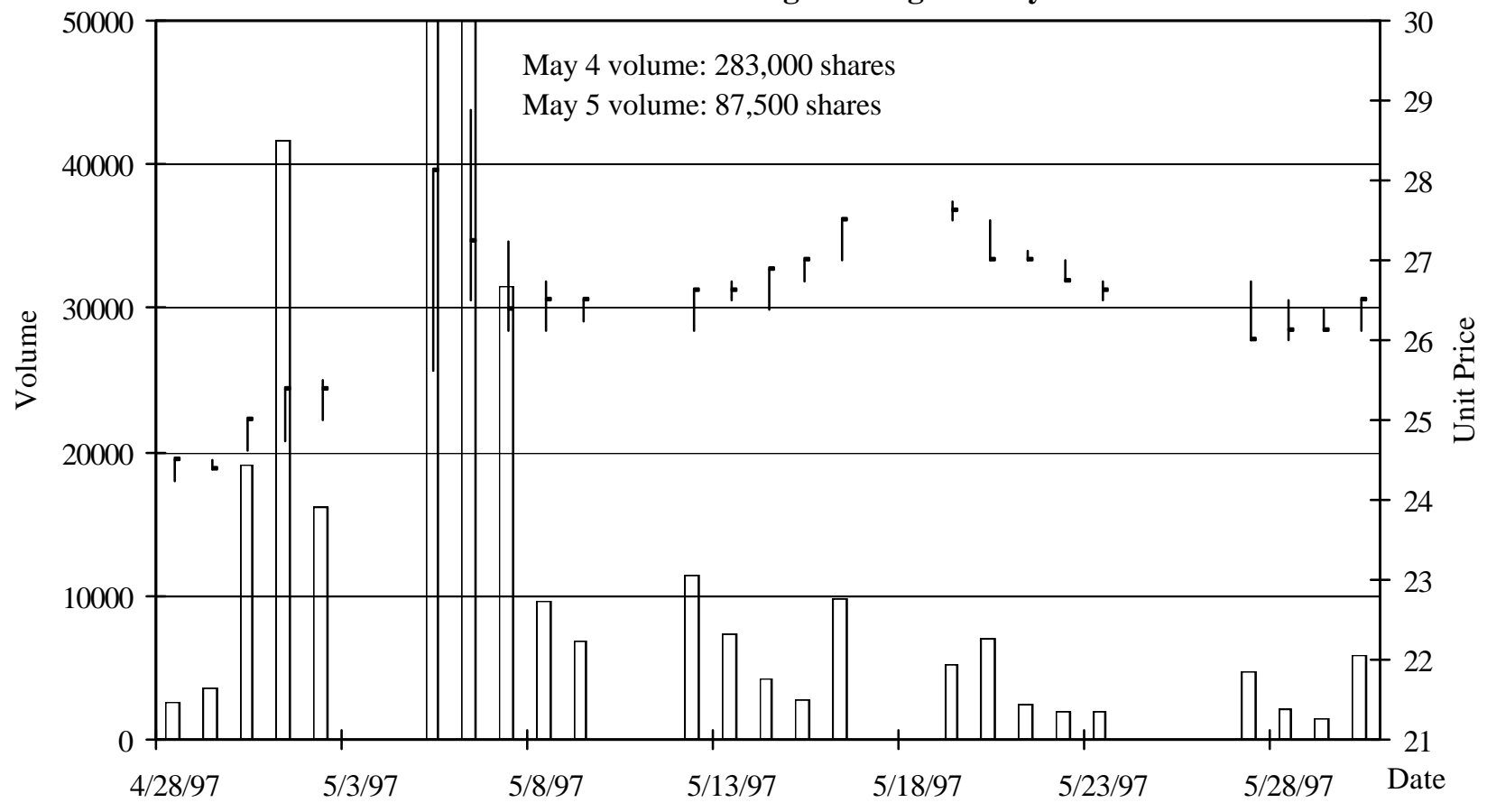

Panel B: Opening and Closing Prices Around Pitino Event

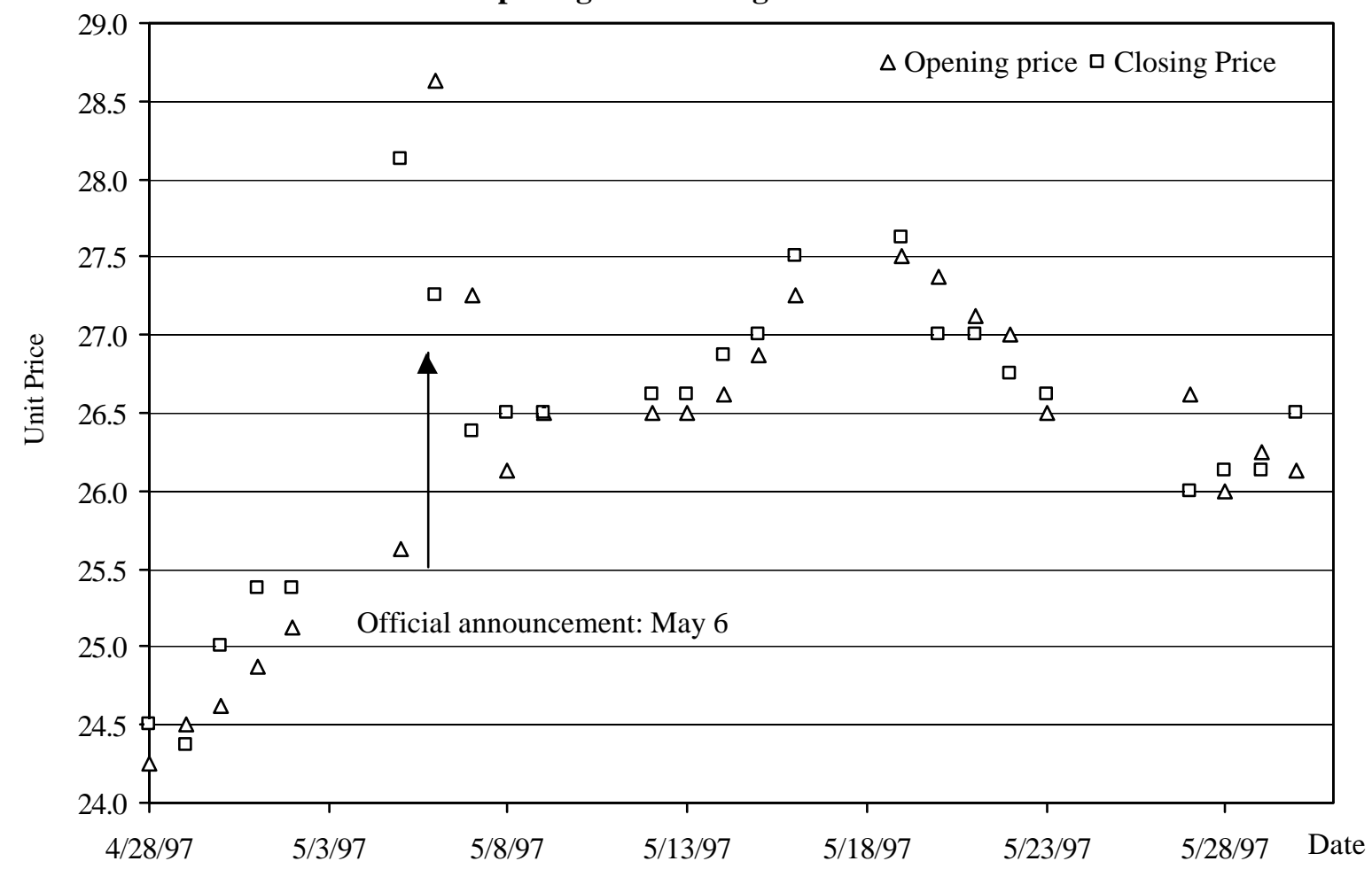

